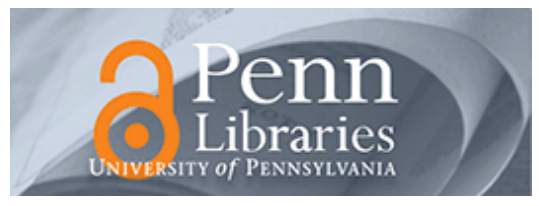

University of Pennsylvania

ScholarlyCommons

Finance Papers

Wharton Faculty Research

3-1986

\title{
The Present Value of Profits and Cyclical Movements in Investment
}

Andrew B. Abel

University of Pennsylvania

Olivier J. Blanchard

Follow this and additional works at: https://repository.upenn.edu/fnce_papers

Part of the Finance Commons, and the Finance and Financial Management Commons

Recommended Citation

Abel, A. B., \& Blanchard, O. J. (1986). The Present Value of Profits and Cyclical Movements in Investment. Econometrica, 54 (2), 249-273. http://dx.doi.org/10.2307/1913150

This paper is posted at ScholarlyCommons. https://repository.upenn.edu/fnce_papers/168

For more information, please contact repository@pobox.upenn.edu. 


\title{
The Present Value of Profits and Cyclical Movements in Investment
}

\author{
Abstract \\ Most of the empirical work on investment is based on the existence of a relation between investment and \\ the expected present val of marginal profits. Thus, in this paper we compute such a present value series, \\ under various assumptions about demand and technology and examine its relation to investment. We find \\ that variations in this present value series are, surprisingly,due more to variations in the cost of capital \\ than to variations in marginal profit. We also find that the present value series, although significantly \\ related to investment, still leaves unexplained a large, serially correlated fraction of investment. \\ Disciplines \\ Economics | Finance | Finance and Financial Management
}


NBER WORKING PAPER SERIES

THE PRESENT VALUE OF PROFITS

AND CYCL.TCAL MOVEMENTS IN INVESTMENT

Andrew B. Abel

Olivier J. Blanchard

Working Paper No. 1122

NATIONAL BUREAU OF ECONOMIC RESEARCH 1050 Messachusetts Avenue

Cambridge MA 02138

May 1983

We thank Andrew Lo for excellent research assistance, the National Science Foundation and the Sloan Foundation for financial support, and Data Resources, Inc., for the use of their computer. We have benefited from helpful comments from Sudipto Bhattacharya, Richard Clarida, Jerry Hausman, John Huizinga, Robert Lucas, Danny Quah, Sherwin Rosen and Larry Summers, and from presentations at the University of Chicago, Harvard University, MIT, University of Rochester, and the National Bureau of Economic Research Program Meeting in March 1982. The research reported here is part of the NBER's research program in Economic Fluctuations and project in Government Budget. Any opinions expressed are those of the authors and not those of the National Bureau of Economic Research. 
The Present Value of Profits and Cyclical Movements in Investment

\section{Abstract}

Most of the empirical work on investment is based on the existence of a relation between investment and the expected present value of marginal profits. Thus, in this paper we compute such a present value series, under various assumptions about demand and technology and examine its relation to investment.

We find that variations in this present value series are, surprisingly, due more to variations in the cost of capital than to variations in marginal profit. We also find that the present value series, although significantly related to investment, still leaves unexplained a large, serially correlated fraction of investment.

Andrew B. Abel

Olivier J. Blanchard

Department of Economics

Littauer Center

Harvard University

Cambridge, MA 02138

(617) 495-2119 


\section{Introduction}

The purpose of this paper is to examine empirically the determinants of the cyclical variability of manucturing investment. The prevailing "neoclassical" theory of investment developed by Jorgenson (1963), and extended by Ha11 and Jorgenson (1967), Eisner and Nadiri (1968), and Bischoff (1971) among others, does not provide a completely satisfactory explanation of the determinants of business investment. The dissatisfaction with the ostimated neoclassical investment equations is not based on the "fit" of these equations or on shifts in these equations; rather, the problem arises from the difficulty of interpreting the estimated distributed lags. Are we to interpret these distributed lags as expectational lags, as delivery lags, or perhaps, more 1ikely, as some convolution of expectational and delivery lags?

An alternative approach to the estimation of investment equations uses the q theory of investment Tobin (1969) which is based on the cost of adjustment 1 iterature developed by Eisner and Strotz (1963), Lucas (1967a, b), Gould (1968), and Treadway (1969). By explicitly modeling the costs of adjustment, which give rise to distributed lagged responses of investment to various shocks, we are led to a clearer distinction between the delivery and/or adjustment lags on the one hand and expectational lags on the other hand. In the estimated q model, the effects of all lagged variables on the expectations of relevant future variables are captured by $q$. The effects of delivery lags on investment would appear as a relation between investment and lagged expectations of q.

Al though the q model appears attractive bocause it distinguishes delivery lags from expectational lags, its empirical performance has not been that 
impressive. Studies which regress investment on q [von Furstenberg (1977), Sumers (1981), Blanchard-Wyplosz (1981)] typically find that q does not explain a large part of the variation in investment and that the unexplained movement in $q$ is highly serially correlated. However, these studies used average $q$ (the value of the firm divided by the replacement cost of its capital) rather than marginal q (the valuation of an additional unit of capital relative to the cost of this capital). The advantage of using average $q$ is that it is based on market value data and relies on the market to calculate the relevant expectations. The disadvantage, of course, is that in situations in which average $q$ and marginal $q$ differ, it is marginal $q$ which is the relevant determinant of investment.

In this paper we study the relation between marginal q and investment. Because marginal $q$ is not directly observable from asset market data, we must construct a series for marginal q before relating investment to marginal q. The construction of the marginal q series is a nontrivial task but provides us with several interesting results, even before we relate marginal q to investment. There are two major problems involved in computing marginal q. The first problem is a standard conceptual question about the appropriate definitions of the cust of capital and marginal profit; we consider alternative sets of assumptions about goods markets and financial markets and calculate a marginal q series for each set of assumptions. The second major problem is technical: we have to compute the expectation of a present value of a strean of marginal profits. Since we treat as random the one-period discount factors, the calculation requires the computations of the sum of expected values of products of random variables. A simple approach to this problem would be to linearize the sum of the products of random variables and then calculate 
its expected value. However, this linearization would not capture the effects of any second-order (or higher) moments. Because we thought that certain cossualces right have important cffects on tiagginal . . i. .ecided to use a quadratic rather than a linear approrimation.

As mentioned above, the calculation of q provides interesting results quite apart from any estimated relation between q and investment. The first result is technical but of some importance for future work. We find that there is a negligible difference between the linear and quadratic approximation to q. That is, taking account of the relevant covariances has very little effect on the calculation of $q$. The other two major results are substantive. We find that the cyclical movement in $q$ is due less to movements in the marginal profits of capital then to movements in the cost of capital. This result is surprising in light of the fact that investment equations typically derive more explanatory power from output or accelerator effects than from cost of capital effects. The final result from the calculation of marginal q is that the cost of capital corponent of q and the marginal profit component aro highly positively correlated.

After constructing the marginal q series, we then investigate the relation between investment and marginal q. Although regressions of investment on q are unlikely to be structural relations, they are a convenient way of sunmarizing sample evidence. The main finding is that, as in the studies cited above, $q$ is generally a significant explanator of investment but leaves unexplained large, serially correlated fraction of investment. Since our findings are so similar to the results obtained relating investment to average $q$, we find little support for the view that the low explanatory power of average $q$ is due to the fact that average $q$ is simply a poor proxy for the 
theoretically more appealing marginal q. We find that output and profit variables still enter significantly when added to our investment equations. The uniformity of results across our different sets of assumptions leads us to conclude that our data are not synpathetic to the basic restrictions imposed by the q theory, even extended to allow for - simple - delivery lags. Whether the problem comes from the assumptions implicit in aggregation, the assumption of homogeneous capital or the assumption of perfect capital markets is a question left for future research.

In section II we develop a model of the optimal investment behavior of a firm and present an expression for marginal q. We also discuss various approximations to marginal q. After describing the construction of the data in section III, we briefly discuss in section IV the estimation of the vector autoregressions used for forecasting the cost of capital and the marginal profitability of capital. In section $V$ we calculate marginal q under various alternative sets of assunptions. We compare the 1 inear and quadratic approximations to marginal $q$, and then compare the relative contribution of the cost of capital variation and the marginal profit variation to the cyclical variations in q. After discussing the observed correlation of the two major components of $q$, we then present the standard errors of estimates of $q$. In section VI, we examine the empirical relation between investment and our constructed series for marginal q. Concluding remarks are presented in section VII.

\section{The Hode1}

Let $\pi_{t}\left(B_{t}, I_{t}\right)$ be the maximized value of the net cash flow of a firm in period $t$, where $K_{t}$ is the stock of physical capital and $I_{t}$ is rate of gross 
investment in physical capital. The variable factors of production have already been "maximized out" in specifying $\pi_{t}\left(K_{t}, I_{t}\right)$. If the firm pays out its net cash flow to its owners each period, then the ex post rate of return, $R_{t}$, to the firm's owners during period $t$ is

$$
\left(1+R_{t}\right)=\left[V_{t+1}+\pi_{t}\left(K_{t}, I_{t}\right)\right] / V_{t}
$$

where $v_{t}$ is the value of the firm at the beginning of period $t$.

Let $\Omega_{t-1}$ denote the set of information available at the beginning of period $t$. Suppose that $v_{t}$ is contained in $\Omega_{t-1}$ but that $v_{t+1}$ and $\pi_{t}$ are not contained in $a_{t-1}$. Taking expectations on both sides of (1) conditional on $\Omega_{t-1}$, we obtain

$$
\left.E\left[V_{t+1}+\pi_{t}\left(K_{t} \cdot I_{t}\right)\right) \mid \Omega_{t-1}\right] / V_{t}=1+E\left(R_{t} / \Omega_{t-1}\right)=1+R_{t} *
$$

where $R_{t}$ * is defined as the ex ante rate of return. This ex ante rate of return is known as of the beginning of $t$ but is stochastic as of earlier periods. Solving equation (2) recursive1y forward and using iterated expectations yields

$$
v_{t}=E\left(\sum_{j=0}^{\infty}\left[\prod_{i=0}^{j}\left(1+R_{t+i} *\right)^{-1}\right] \pi_{t+j}\left(K_{t+j}, I_{t+j}\right) / \Omega_{t-1}\right]
$$

We assume that the firm makes its investment decisions so as to maximize $v_{t}$. In choosing the optimal rate of investment, we snppose that the firm takes the joint conditional distribution of the sequence of discount factors $\left(1+R_{t+i}\right)^{-1}$ as given. ${ }^{1}$ The firm maximizes $V_{t}$ subject to the capital

1. This is a plausible assumption. Firms are justified to do so, however, nnder the fairly restrictive assumption of multiplicative uncertainty. Another approach which would not lead to this difficulty rould be to use a consumption based valuation (Breeden [1979]):

$$
q_{t}=E\left[\left.\sum_{i=0}^{\infty} \gamma^{i} \frac{U^{\prime}\left(C_{t+i}\right)}{U^{\prime}\left(C_{t}\right)}\right|_{t+i} \Omega_{t-1}\right]
$$


accumulation condition

$$
K_{t}=(1-\delta) K_{t-1}+I_{t}
$$

The optimal rate of investment is such that a small change in $I_{t}$ ill not change the expected present value of net cash flow. That is, the marginal cost of investment must be equal to the expected present value of marginal profits to capital.

$$
\begin{gathered}
-E\left(\frac{\partial \pi_{t}}{\partial I} l_{t} n_{t-1}\right)=q_{t} \\
\text { where } \quad q_{t}=E\left[\sum_{j=0}^{\infty}\left[\prod_{i=0}^{j}\left(1+R_{t+i} *\right)^{-1}\right] \frac{\partial \pi_{t+j}}{\partial X_{t+j}}(1-\delta){ }^{j} l_{t-1}\right\}
\end{gathered}
$$

Following the adjustment cost 1 iterature developed by Eisne: and Strotz (1963), Lucas (1967a, b), Gould (1968) and Treadway (1969), we assume that $\frac{\partial \pi_{t}}{\partial I_{t}}<0$ and $\frac{\partial^{2} \pi_{t}}{\partial I_{t}^{2}}<0$. That is, the marginal cost of investment, $\frac{-\partial \pi_{t}}{\partial I_{t}}$, is a positive and increasing function of $I_{t}$ so that (5a) implies that investrent is an increasing function of $q_{t}$.

For expositiona clarity it will be useful to define $\beta_{t+i}=\left(1+R_{t+i}\right)^{-1}(1-\delta)$ as the ex-ante one-period discount factor and $M_{t+j}=(1-\delta)^{-1} \frac{\partial \pi_{t+j}}{\partial r_{t+j}}$ as the marginal profit of capital in period $t+j$. Therefore, equation ( $5 b$ ) can be written as

$$
\begin{gathered}
q_{t}=E\left[q_{t} * \mid \Omega_{t-1}\right] \\
q_{t} *=\sum_{j=0}^{\infty}\left[\prod_{i=0}^{j} \beta_{t+i}\right] M_{t+j}
\end{gathered}
$$

Wo wanted our study to be easily comparable to other work on investment and decided to use a standard cost of capital variable. The methods used in this paper could be applied to (*) also. (Such an application would require a specification of the utility function and an appropriate measure 
From (6) it is clear that the calculation of $q_{t}$ requires the computation of expectations of long products of random variables. In this paper we present a procedure for calculating a series which is an approximation to $q_{t}$ in (6a). $\Lambda$ very simple approximation procedure would be simply to linearize $q_{t}$. Howover, this linear approximation would ignore all second-order (and higher order) moments. Since we are interested in the effect of the covariance of the discount factor and the marginal profit, for example, we will use a quadratic approximation. For expositional reasons, we derive the 1 inear approximation to $q_{t}$ in the text, but present the derivation of the quadratic approximation in Appendix A.

We 1 inearize $q_{t}$ around $\beta_{t+i}=\bar{\beta}$ and $H_{t+i}=\bar{H}, i=0,1,2 \ldots$ where $\bar{f}$ and IT are the sample means of $\beta_{t}$ and $\|_{t}$ respectively:

$$
\begin{gathered}
\mathbf{q}_{\mathbf{t}} * \approx \bar{q}+\bar{M}(1-\bar{\beta})^{-1} \sum_{j=0}^{\infty} \bar{\beta}^{j}\left(\beta_{t+j}-\bar{\beta}\right)+\sum_{j=0}^{\infty} \bar{\beta}^{j+1}\left(M_{t}+j-\bar{M}\right) \\
\text { where } \bar{q}=\overline{M j}(1-\bar{\beta})^{-1}
\end{gathered}
$$

In order to calculate $q_{t}$ we must calculate expectations of both sides of (7a) conditional on $\Omega_{t-1}$. This calculation requires a stochastic specification of $\beta_{t+j}$ and $\|_{t+j}$. Recall that $\beta_{t}$ is the ex-ante one-period discount factor $\left(1+E\left(R_{t} \mid \Omega_{t-1}\right)\right)^{-1}(1-\delta)$. Let $\tilde{\beta}_{t}=\left(1+R_{t}\right)^{-1}(1-\delta)$ be the ex-post one-period discount factor. We adopt the following stochastic specification: $\tilde{\beta}_{t}$ and $H_{t}$ are each generated as linear combinations of the elements of some observable vector $Z_{t}$ which evolves according to vector autoregression. Formally, we suppose that

of consumption.) 


$$
\begin{aligned}
& \tilde{\beta}_{t}=b^{\prime} Z_{t} \\
& M_{t}=a^{\prime} Z_{t}
\end{aligned}
$$

where a and $b$ are vectors of known constants and

$$
\begin{aligned}
Z_{t}-\bar{Z}=A\left(Z_{t-1}-\bar{Z}\right)+\varepsilon_{t} \quad & E\left(\varepsilon_{t}\right)=0 \\
& E\left(\varepsilon_{t} \varepsilon^{\prime}{ }_{s}\right)=l_{0}^{\bar{z} \text { if } t=s}
\end{aligned}
$$

The assumption in (9) that $z_{t}$ evolves according to a first-order process is not restrictive. The autoregression in (9) could be the companion form of a higher order vector autoregression; in this case many of the rows of A correspond to identities and many elements of $\Sigma$ are identically zero.

This stochastic specification is introduced in order to calculate the expectation of (7a) conditional on $\Omega_{t-1}$. Since $\beta_{t}=E\left(\tilde{\beta}_{t} \mid a_{t-1}\right)$ it follows from ( $8 a)$ and (9) that

$$
\beta_{t}-\bar{\beta}=b \cdot A\left(Z_{t-1}-\bar{Z}\right) \quad ; \bar{\beta}=b \cdot \bar{Z}
$$

Using ( $8 \mathrm{~b})$, (9) and (10), the conditional expectations of the terms on the right hand side of (7a) are easily calculated

$$
\begin{aligned}
& E\left(\beta_{t+j}-\bar{\beta} \mid \Omega_{t-1}\right)=b \cdot A^{j+1}\left(Z_{t-1}-\bar{z}\right) \\
& E\left(M_{t+j}-\bar{M} \Omega_{t-1}\right)=a \cdot A^{j+1}\left(Z_{t-1}-\bar{z}\right)
\end{aligned}
$$

Using (11a,b) we can calculate the expectation of $(7 a)$ conditional on $a_{t-1}$

$$
\begin{aligned}
q_{t} & =E\left(q_{t}^{*} \mid \Omega_{t-1}\right) \approx \bar{q}+L(\beta)+L(H) \\
L(\beta) & =\bar{M}(1-\bar{\beta})^{-1}{ }_{b} \cdot(I-A \bar{\beta})^{-1} A\left(Z_{t-1}-\bar{Z}\right) \\
L(M) & =\bar{\beta}_{a} \cdot(I-A \bar{\beta})^{-1} A\left(Z_{t-1}-\bar{Z}\right)
\end{aligned}
$$

The term $L(\beta)$ in the linear approximation to $q_{t}$ captures the first-order offects on $q_{t}$ of variability in the cost. of capital. It is a weighted sum of expected deviations of ex ante discount factors (which in this case is the 
same as expected deviations of ex post discount factors) from their mean, with exponentially decreasing weights.

Similarly, L(M) ceptures the first-order effects on $q_{t}$ of variability in the marginal profit of capital. It is a weighted sun of expected deviations of marginal profits from their mean. The weights decline geometrically at the same rate that the weights in $L(\beta)$ decine.

In Appendiz $A$ we derive expressions for the quadratic terms $Q(\beta, \beta)$ and $Q(\beta, M)$ which capture the effects of the conditional covariances between different ex ante discount factors, and between ex ante discount factors and marginal profits, respectively. These covariances are conditional covariances around unconditional means; they depend on $Z_{t-1}$ and therefore move througl time. Note that since $q_{t}$ is linear in $H_{t+i}$, the quadratic term Q(M, $H_{)}$is identical1y zero.

\section{The Data}

In this section we describe the construction and use of the econonic time series used in the construction of several different time series for $q_{t}$ We use quarterly data for aggregate U.S. manufacturing 1948:2 to 1979:3 and fit this data to a 4-th order vector autoregression. Thus, in the first order system in equation (9), $Z^{\prime}{ }_{t}=\left(Z^{*}{ }_{t}, Z^{*}{ }_{t-1}, Z^{*}{ }_{t-2}, Z^{* \prime} t-3^{\prime}\right.$ where $Z^{*}$ contains either 5 variables or 7 variables depending on how much information we put in the information set $\Omega$. The definition and construction of the individual elements of $Z^{*}$ are discussed below. 


\section{The Discount Factor}

The first two elements of $Z^{*}{ }_{t}$ are used in the measurement of the ex post discount factor $\tilde{\beta}_{i}$. To motivate the definitions of $Z_{1 t}$ and $Z_{2 t}$ we observe that

$$
\tilde{\mathrm{e}}_{\mathrm{t}} \approx 1-\mathrm{R}_{\mathrm{t}}-\delta
$$

where $R_{t}$ is the real ex post rate of return to the owners of the firm. Recognizing that firms are financed by both debt and equity, we 1 et $Z^{*}{ }_{1 t}$ and $Z^{*} 2 t$ be the ex post equity and debt discount factors, respectively:

$$
\begin{gathered}
Z_{1 t}^{*} \equiv 1-R E_{t}+\dot{P}_{m t} / P_{m t}-\delta_{t} \\
Z_{2 t}^{*} \equiv 1-\left(1-\tau_{t}\right) R D_{t}+\dot{P}_{m t} / P_{m t}-\delta_{t}
\end{gathered}
$$

The definitions of $Z^{*}{ }_{1 t}$ and $Z^{*}{ }_{2 t}$ reflect the fact that interest payments on debt are tax deductible and that the depreciation rate is not constant. RE is the ex post rate of return on equity, calculated as the sum of the dividend price ratio and the rate of capital gain on the $S 8 p 400$. RD $t$ is the rate of return on debt, measured by the rate of return on commercial paper.* $\tau_{t}$ is the corporate income tax rate. $\delta_{t}$ is the physical depreciation rate computed as a weighted average of the depreciation rates of structures and equipment for U.S. manufacturing capital stock. $\dot{\mathrm{P}}_{\mathrm{mt}} / \mathrm{P}_{\mathrm{mt}}$ is the rate of price inflation of manufactured goods, measured by the rate of change of the wholesale price index.

The ex post discount factor is a weighted average of the ex post equity and debt discount factors

* A better measure would be the weighted average of the one-period rates of return on private bonds of different maturities, with weights corresponding to the proportions of debt of different maturities in total debt. 


$$
\tilde{\beta}_{t}=a Z * 1 t+(1-a) Z * 2 t
$$

where $a$ is the share of equity finance, which has decreased over the sample period. We have chosen to examine the behavior of $q_{t}$ under two alternative values for $a(a=0.5$ and $a=0.3)$ to determine whether the computation of $q_{t}$ is sensitive to the value chosen for a.

\section{Marginal Profit}

In order to measure the marginal profit of capital we need to make some assumptions about technology and about the demand curves facing manufacturing firms. We assume that capital is homogeneous and any technological progress is disembodied so that the marginal profit $\|_{t}$ does not depend on the dates at which capital was installed. We also assume that the production function is linearly homogeneous in capital, investment, and the variable factors of production.

We have chosen to make two alternative assumptions about the demand curves facing manuacturing firms. Our first assumption is that manuacturing firms are perfectly competitive. That is, they are price-takers and face no quantity constants in output markets or factor markets. Under these assumptions the marginal profit of capital $M_{t}^{u}$ (u for unconstrained) is simply equal to the average profit of capita $1 .{ }^{2}$ In this case, $\|_{t}^{u}$ is computed as

$$
I_{t}^{u}=Z_{4 t}^{*}-Z^{*} 3 t
$$

2. Suppose that as in Lucas (1967a) $\pi(K, I)=\max [p F(K, L)-$ wL - c(I,K) $\}$ where $F()$ is 1 inearly homogeneous in $K$ and $L$ and $L()$ is 1 inearly homogeneous in $I$ and $K$. Observe from Euler's theoren that $\pi(K, I)=p F_{K}(K, L) K-c(I, K)$ and that $\frac{\partial \dot{\pi}}{\partial K}=\mathrm{pF}_{\mathrm{K}}(\mathrm{K}, \mathrm{L})-\frac{\partial \mathrm{c}}{\partial K}$. Our statement that the marginal profit of capital is equal to the average product of capital (pF(K,L) - wL)/K is true only if $\partial \mathrm{c} / \partial \mathrm{K}$ is zero. However this restriction is not compatible with the assumption that the production-cum-adjustment cost function is linearly homogeneous in capital, investment and the variable factors of production. Nonetheless we ignore the cyclical variations in $\partial c / \partial K$. 


$$
\begin{aligned}
& \text { where } Z_{3 t}^{*} \equiv\left(1-\tau_{t}\right)\left(W_{t} L_{t} / P_{K t} K_{t}\right) \\
& Z^{*}{ }_{4 t} \equiv\left(1-\tau_{t}\right)\left(P_{1 n t} Y_{t} / P_{K t} K_{t}\right)
\end{aligned}
$$

and $Y_{t}, K_{t}$, and $W_{t} L_{t}$ are the output, capital stock, and nomiual wage bill, respectively, of the manuacturing sector. $P_{K t}$ is the nominal price of capital.

The alternative assumption is that firms may have faced binding output constraints during the sample period. In this case, the marginal profit of capital is equal to wage savings accruing to an additional unit of capital, which is equal to the wage rate multiplied by the marginal rate of substitution of labor for capital. In general, calculations of a series of marginal profits would require a complete specification of technology. Here we assume that the production function is additively separable in capital and labor on the one hand and other factors of production on the other hand. Futhermore we suppose that the elasticity of substitution between capital and labor, denoted by $\sigma$, is constant. In this case, marginal rate of substitution of labor for capital is proportional to $\left(\mathrm{L}_{t} /\left(\mathrm{P}_{\mathrm{Kt}} / \mathrm{P}_{\mathrm{mt}}\right) \mathrm{K}_{t}\right)^{\frac{1}{\sigma}}$. Therefore, the after-taxmarginal profit of capital, $M_{t}^{c}(\sigma)$ can, except for a constant of proportionality, be written as

$$
H_{t}^{c}(\sigma)=Z_{3 t}^{*}(\sigma)=\left(1-\tau_{t}\right)\left(\frac{W_{t}}{P_{m t}}\right)\left(\frac{L_{t}}{\left(P_{K_{t}} / P_{m t}\right) K_{t}}\right)^{\frac{1}{\sigma}}
$$

where $W_{t}$ is the nominal wage rate and $L_{t}$ is the number of person-hours employed. 3

3. Observe that when $\sigma=1, M_{t}^{c}(1)=\left(1-\tau_{t}\right)\left(W_{t} L_{t} / P_{K_{t}} K_{t}\right)$, which is equal to the value of $Z^{*} \mathrm{~F}_{\mathrm{t}}$ in the unconstrained case (16a). However, in our work, these two series are not identically equal because in (16a) we use data on the nominal wage bill W $\mathrm{L}_{\text {t }}$ obtained from Table 2.1 of the National Incone and Product Accounts: Wage and Salary Disbursements-Manufacturing. In order to compute (17), we need separate data on $W_{t}$ and $L_{t}$, in general. 
Figures C-1 to C-4 in Appendix $C$ present the time series for $\tilde{\beta}_{t}, H_{t}^{u}$ and $M_{t}^{c}$. The ex post discount factor $\tilde{\beta}_{t}$ has no clear time trend but both $M_{t}^{u}$ and $M_{t}^{c}$ have strong trends. Since our focus is on the cyclical behavior of $M_{t}, \beta_{t}$ and $q_{t}$. we will detrend all variables first. Therefore, it should be noted that this paper has nothing to say about trend movements or about the level of $q_{t}$.

\section{Additional Elements of $Z^{*}$}

In addition to $Z^{*}{ }_{i t} i=1,2,3,4$, defined above, the vector $Z^{*}$ includes the following three variables

$$
\begin{aligned}
Z^{*}{ }_{5 t} & =\dot{\mathrm{P}}_{\mathrm{mt}} / \mathrm{P}_{\mathrm{mt}} \\
\mathrm{Z}^{*}{ }_{6 \mathrm{t}} & =\mathrm{q}_{\mathrm{t}}^{\mathrm{F}} \\
\mathrm{Z}^{*}{ }_{7 t} & =I_{t} / \mathrm{K}_{\mathrm{t}}
\end{aligned}
$$

where $q_{t}^{F}$ is the average valuation of capital based on a series constructed by von Furstenberg (1977) from asset market data and $I_{t} / K_{t}$ is the ratio of investment to the capital stock for the manufacturing sector. We do not use von Furstenberg's q series because his series covers only the period 1953:1 to 1976:4. However, we followed his procedure to construct a similar average $q$ series for the period 1947:2 to 1979:3. For the time period for which we have data both on von Fnrstenberg's $q$ and our constructed $q_{t}^{F}$ the correlation between the two series is .971 .

The variables $Z^{*}{ }_{5 t}, Z^{*} 6 t$ and $Z^{*}{ }_{7 t}$ are inclnded in the vector autoregres-

These data are obtained from U.S. Employment and Earnings Balletin 1312-11 from the U.S. Department of Labor using the series for: (1) productionworker average weekly hours - manufacturing; (2) production workers manufacturing: and (3) production-worker average hourly earnings. As it turns out, the nominal wage bill from the National Income and Product Accounts is not precisely equal to the product of the series (1), (2) and (3) obtained from Bulletin 1312-11. Thus our series for $H_{t}^{u}$ and $H_{t}^{c}(1)$ are not equal to each other. 
sions because they may help predict $\beta_{t+i}$ and $\mu_{t+i}$. The work of Modigliani and Shiller (1973) suggests that both lagged rates of inflation and lagged rates of interest help predict future rates of interest. Also, $q^{F}$ and $I / K$ are likely to contain information which will help pructet marginal profits and interest rates. To complere our specification of $q_{t}$, we must specify a and $b$, the vectors of known constants in $(8 a, b)$. It follows immediately from (15) that $\tilde{\beta}_{t}=b^{\prime} Z_{t}$ where

$$
b^{\prime}=\left[\begin{array}{llllll}
a & 1-a & 0 & 0 & \cdots & 0
\end{array}\right]
$$

As for the vector a in the relation $l_{t}^{\prime}=a^{\prime} Z_{t}$, it follows immediately from (16) and (17) that

$$
\begin{aligned}
& a^{\prime}=\left[\begin{array}{llllllll}
0 & 0 & -1 & 1 & 0 & 0 & \cdots & 0
\end{array}\right] \quad \text { if } H_{t}=s_{t}^{u} \\
& a^{\prime}=\left[\begin{array}{llllllll}
0 & 0 & 1 & 0 & 0 & 0 & \cdots & 0
\end{array}\right] \quad \text { if } M_{t}=M_{t}^{c}
\end{aligned}
$$

\section{Estimation of the VAP's}

In order to calculate the quadratic approximation to $q_{t}$ we must estimate the coefficient matrix $A$ and the disturbance covariance matrix $\Sigma$ in (9). For each definition of marginal profit, we estimate two alternative vector autoregressions corresponding to two different information sets: $\Omega^{s}$ (s for sma11) and $\Omega^{L}$ (L for 1arge). The 1arge information set $\Omega_{t-1}^{L}$ consists of the 28 variables $Z^{*}{ }_{i, t-j}, i=1, \ldots, 7 ; j=1,2,3,4$. In this case, the vector $Z_{t}$ in (9) is a $28 \times 1$ vector, $A$ is a $28 \times 28$ matrix in which only the first 7 rows are non-trivial, and $\Sigma$ is a $28 \times 28$ matrix which is identically zero except for the $7 \times 7$ matrix in the upper left corner.

Alternatively, we use the small information set $\Omega_{t-1}^{s}$ which consists of the 20 variables $Z^{*}{ }_{i, t-j} i=1, \ldots 5 ; j=1,2,3,4$. In this case, of course, $Z_{t}$ 
is $20 \times 1$, A is $20 \times 20$ with only 5 non-trivial rows and $\Sigma$ is $20 \times 20$ with nonzero elements only in the $5 \times 5$ matrix in the upper left corner. The reason for excluding $Z^{*} 6, t-j$ and $Z^{*}{ }_{7, t-j}$ from the information set $\Omega_{t-1}^{s}$ is that we want to compare our constructed $q_{t}$ series to an asset-market-based q series (our $q_{t}^{F}$ series). We also want to characterize the relation of our constructed $q_{t}$ series to the investment capital ratio. Therefore, including $q_{t}^{F}$ and $I_{t} / K_{t}$ in the information set would obscure the comparison between the two q series.

A detailed discussion of the estinated parameters in the two vector autoregressions would be of little interest; we simply note here that all of the eigenvalues of A lie well inside the unit circle. (All variables are first exponentially detrended.)

Table $I$ in the text reports the $\vec{R}^{2}$ statistics for each of the equations for each of six vector autoregressions. Three VAR's were run for each information set $\Omega_{s}$ and $\Omega_{L}$. For each information set we ran 3 different VAR's corresponding to three different values for $Z_{3}$ as explained in $T a b l e ~ I$ (these three different definitions of $z_{3}$ correspond to three different definitions of the marginal profit of capital: $M_{u}, H_{c}$ with $\sigma=0.5$, and $H_{c}$ with $\left.\sigma=1.0\right)$. The two results worth noting are the consistently low $\bar{R}^{2}$ for $Z_{1}$, the ex post equity discount factor, and the consistently high $\vec{R}^{2}$ for $Z_{2}$, the ex post debt discount factor. The low $\overline{\mathfrak{R}}^{2}$ for $\mathrm{Z}_{1}$ is to be expected given the large movements in stock prices and the resulting large rates of capital gain or loss.

\section{v. Calculation and Decomposition of Marginal g}

In this section we use the estimated parameters of the vector autoregres- 
Table 1

Vector Autoregressions: $\overline{\mathrm{R}}^{2}$

$1948: 2$ to $1979: 3$

Dependent Variable

$\mathrm{z}_{1}$
$\mathrm{z}_{2}$
$\mathrm{z}_{3}$
$\mathrm{z}_{4}$
$\mathrm{z}_{5}$
$\mathrm{z}_{6}$
$\mathrm{z}_{7}$

$$
M^{\mathrm{u}} \quad \frac{5 \text { Variables in } \mathrm{Z}}{\mathrm{M}^{\mathrm{C}}: \sigma=0.5 \mathrm{M}^{\mathrm{C}}: \sigma=1.0}
$$$$
.073 \quad .058
$$$$
.656
$$$$
.894
$$$$
.662
$$$$
.046
$$$$
.675
$$$$
.849
$$$$
.890
$$$$
.885
$$$$
.642
$$$$
.662
$$$$
.903
$$$$
.884
$$$$
.675
$$$$
.675
$$$$
-
$$$$
-
$$

$\begin{array}{ccc} & 7 \text { Variables } \text { In } Z \\ M^{\mathrm{u}} & \mathrm{M}^{\mathrm{c}}: \sigma=0.5 & \mathrm{M}^{\mathrm{c}}: \sigma=1.0 \\ .060 & .050 & .055 \\ .697 & .678 & .697 \\ .899 & .858 & .904 \\ .897 & .886 & .887 \\ .695 & .677 & .699 \\ .966 & .965 & .966 \\ .958 & .956 & .957\end{array}$

$z_{1}$ : ex post equity discount factor

$\mathrm{z}_{2}$ : ex post debt discount factor

$\mathrm{Z}_{3}$ : after-tax wage bill divided by capital, if $M=\mathrm{M}^{\mathrm{u}}$

: after-tax real wage rate multiplied by marginal rate of substitution, if $M=M^{c}$

$z_{4}$ : after-tax output divided by capital

$\mathrm{Z}_{5}$ : rate of wholesale price inflation

$\mathrm{z}_{6}$ : value of average $\mathrm{q}$

$\mathrm{z}_{7}$ : ratio of investment to capital 
sions to calculate 12 different time series for $q_{t}$. There are 12 different series for $q_{t}$ because we use 2 alternative assumptions for the shere of equity in total financing $(a=0.5, a=0.3), 3$ alternative assumptions for the calculation of the marginal profit of capital $\left(M_{t}^{u}, M_{t}^{c}\right.$ for $\sigma=0.5$ and $"_{t}^{c}$ for $\sigma=1.0)$ and two alternative information sets $\left(\Omega^{s}, \Omega^{L}\right)$. For each of these twelve q series we ask the following questions. Are the conditional covariance effects in the quadratic terms $Q(\beta, \beta)$ and $Q(\beta, \mu)$ empirically important? How much of the cyclical variability in $q_{t}$ is due to variability in the cost of capital and how much is due to variability in the marginal profit of capital? Are the variations in $q_{t}$ resulting from variation in the ex ante cost of capital variability positively or negatively correlated with the variations in $q_{t}$ resulting from variability in expected marginal profits?

\section{The Empirical Importance of the Quadratic Terms}

A comparison of the fourth and fifth colunns of Table 2 reveals that the quadratic terms $Q(\beta, \beta)$ and $Q(\beta, H)$ are not very important empirically. For each of the 12 calculated series for $q_{t}$, the standard deviation of the linear approximation to $q_{t}$ is roughly equal to the standard deviation of the quadratic approximation to $q_{t}$; that is, the inclusion of the quadratic terms $Q(\beta, \beta)$ and $Q(\beta, H)$ has hardly any effect at all on the standard deviation of $q_{t}$. Furthermore, the 1 ast column of Table 2 reveals the nearly perfect correlation between linear q and quadratic $q$. For a more detailed examination of the role of the quadratic terms, we examine a particular $q_{t}$ series: $a=0.5$, $M_{t}=M_{t}^{u}$, and $\Omega=\Omega^{L}$. For this series, the standard deviations of $Q(\beta, \beta)$ and $Q(\beta, M)$ are .0026 and .0036 respectively; their correlation is .400 so that the standard deviation of their sum is .0052 , which is equal to $5.1 \%$ of the standard deviation of the full quadratic approximation. The correlation between 
Table 2

Standard Deviations

and Correlations

$L(\beta) \quad L(M) . \quad \rho \quad$ Linear $q$ Quadratic $q \quad \rho^{*}$

$\Omega=\Omega^{S}$

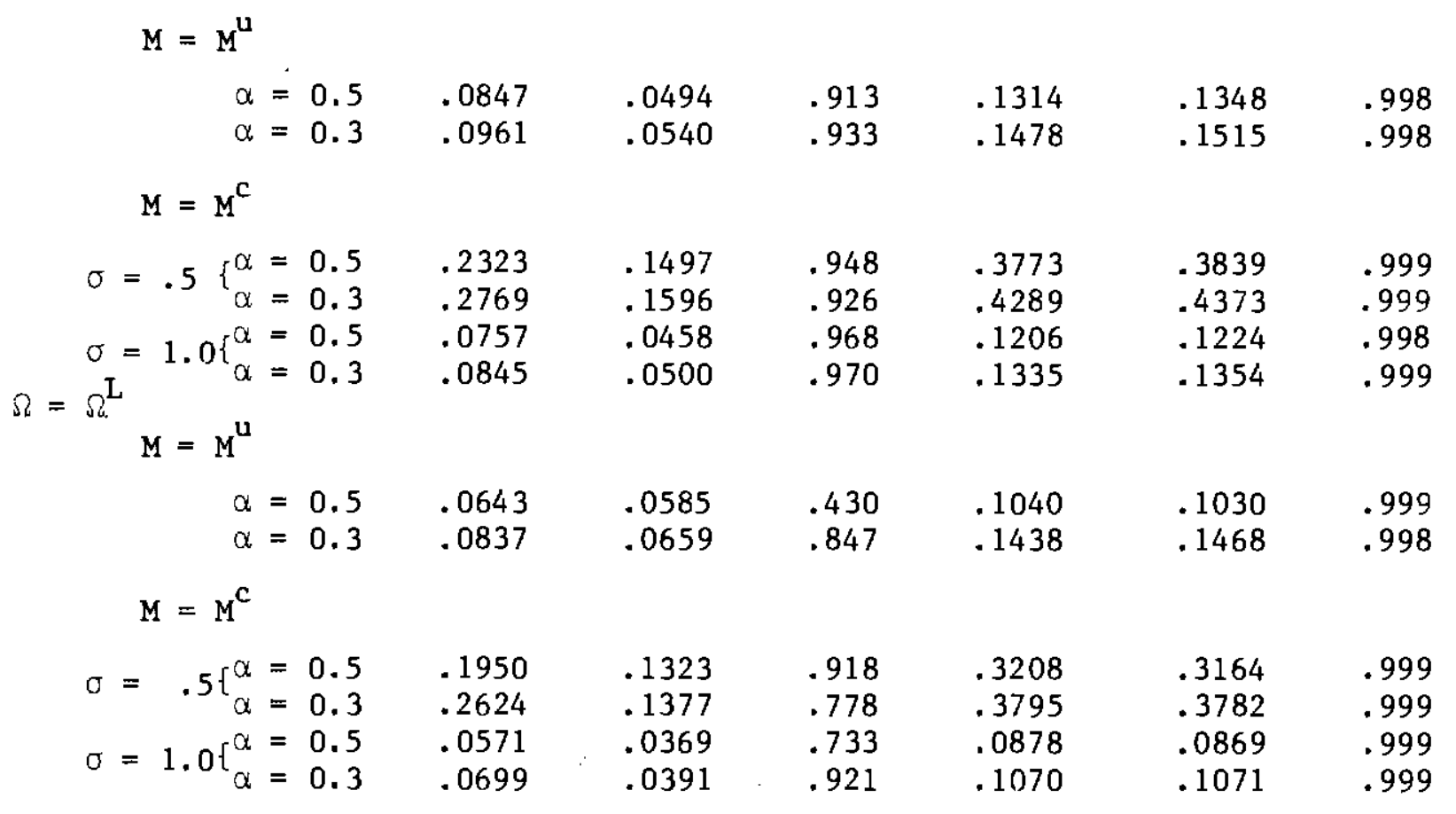

$$
\begin{aligned}
& \text { Linear } q=\bar{q}+L(\beta)+L(M) \\
& \text { Quadratic } q=\bar{q}+L(\beta)+L(M)+Q(B, \beta)+Q(\beta, M) \\
& \rho=\text { Correlation }[L(\beta), L(M)] \\
& \left.\rho^{*}=\text { Correlation [linear } q, \text { quadratic } q\right]
\end{aligned}
$$


$(Q(\beta, \beta)+Q(\beta, H))$ and $(L(\beta)+L(M))$ is -.20 .

The result that the quadratic approximation to $q_{t}$ does not differ substantially from the linear approximation to $q_{t}$ is important for future research on investment and perhaps on asset prices in general, To be feasible, efficient methods of estimation of models under rational expectations require these models to be linear or linearized. Our findings above suggest that although the initial specification of $q_{t}$ is highly nonlinear, a linear approximation appears to be acceptable. Iu the remainder of this section, we consider the linear approximat.ur. $\bar{q}+L(\beta)+L(K)$ and refer to it as linear $q_{t}$

The Contributions of $\beta$ and $l 1$ to Variability of $q$

Our calculated q series exhibit variation over time because both the discount factor $\beta$ and the marginal profit ll vary over time. Based on the fact that most empirical studies of investment find a strong relation between investment and some measure of output or profit, but find a weaker relationship between investment and the cost of capital, we expected to find most of the variability in $q$ would be due to variability in M rather than variability in $\beta$. As explained below, we found the opposite to be true.

Recall that $L(\beta)$ is the linear approxisction to the q series based on the assumption that only $\beta$ varies over time and that $\|$ remains constant. Similarly $L(H)$ is the linear approximation to the q series based on the assumption that the cost of capital $\beta$ remains constant and only the marginal profit $u$ varies over time. The standard deviations of $L(\beta)$ and $L(M)$ are presented in columins one and two, respectively, of Table 2 . In every one of the 12 cases in Table 2, we find that the standard deviation of $L(\beta)$ exceds the standard 
of $L(M)$; often the difference is quite substantial. In general, we find that calculating the $q$ series under the assumption that $\beta$ is constant will reduce the standard deviation of the q series by a factor of 2 or 3 . This result contrasts sharply with our a priori beliefs expressed above.

The finding that the standard deviation of $q$ is reduced by a factor of 2 or 3 when we suppress the variation in the discount factor may shed some 1 ight on volatility tests of asset pricing models. These volatility tests are based on the assumption that, for instance, stock prices are equal to the expected present value of dividends. Using this assumption, and the assumption that the discount factor is constant, one derives a relation between the variability of dividends and the variability of stock prices. Typically, actual stock prices exhibit much greater variability than implied by variability in dividends, holding the discount factor constant. Our findings indicate that, in a different context, constraining the discount factor to be constant leads one to understate the standard deviation of the expected present value series by a factor of 2 or 3 . That is, the assumption of a constant discount factor is far from innocuous.

The correlation of $L(\beta)$ and $L(H)$ is presented in the third column of Table 2. In every one of the 12 cases presented in Table 2, $L(\beta)$ and $L(H)$ have positive correlation, and in 10 of the 12 cases the correlation exceeds .75. Thus we find that $L(\beta), L(M)$ and by implication $q$, move cyclically together. That is, periods in which the sequence of expected marginal products is high tend to be periods in which the sequence of expected discount factors is high, or equivalently, periods in which the sequence of expected costs of capital is 1 ow. As will be shown below, this does not imply that the one-period expected discount factor moves cyclically with $L(H)$. Rather it 


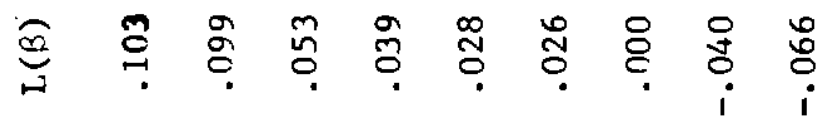

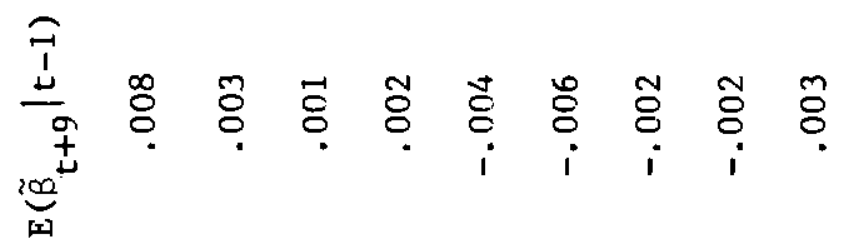

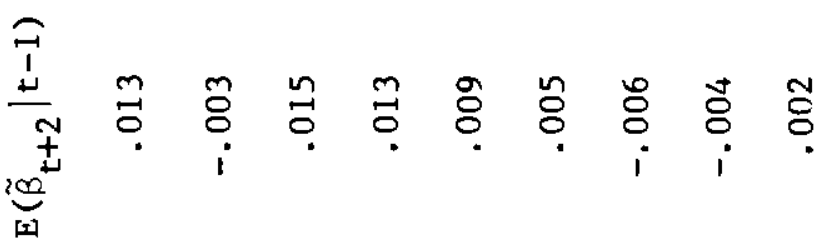

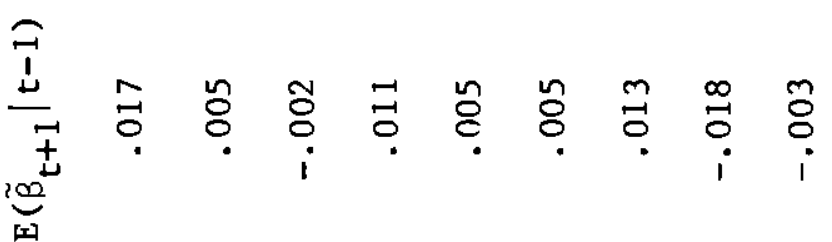

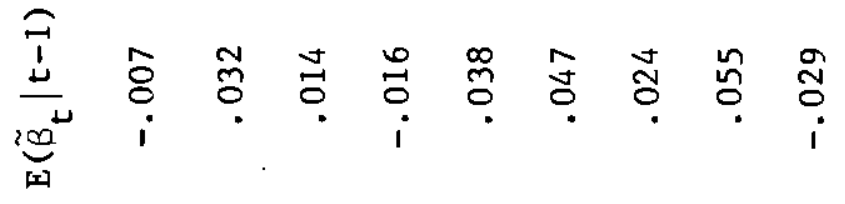

$$
\begin{aligned}
& \text { m }
\end{aligned}
$$

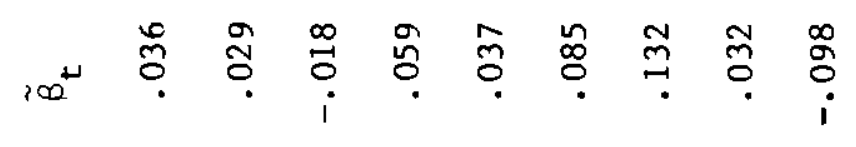

$$
\begin{aligned}
& \begin{array}{l}
\text { n } \\
\text { i }
\end{array} \\
& \text { n } \\
& \text { c }
\end{aligned}
$$

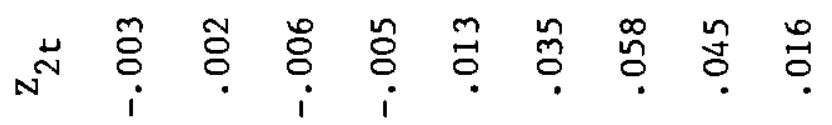

$$
\begin{aligned}
& = \\
& \text { II }
\end{aligned}
$$

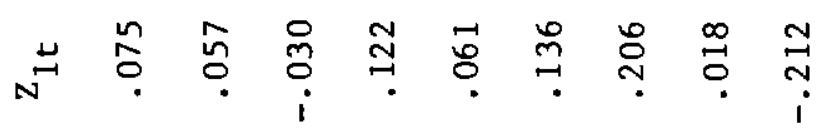

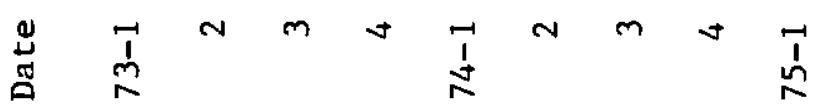


implies that the appropriate weighted average of expected discount factors moves cyclically with $L(M)$. (Note that since $\bar{\beta}$ is approximately 0.97 , the relative weight of the first one-period discount factor in the weighted sum $L(\beta)$ is approximately equa 1 to 0.03$)$.

Our finding that $L(\beta)$ exhibits a substantial cyclical variability and is highly correlated with $L(M)$ is somewhat surprising. One right argue, and we initially thought, that this finding might be a spurious result which is a consequence of our vector autoregression approach. Recall that $\beta_{t}$ depends, with weight $a$, on the expected equity discount factor $E\left(Z_{1 t} \mid \Omega_{t-1}\right)$. As discussed earlier, the equation for $Z_{1 t}$ has essentially no explanatory power; however, our formulae for $q$ use the point estimates of the right hand side variable in this equation and these point estimates differ from zero. Thus it is possible that large realizations of the right hand side variables may indicate - incorrectly, if the true coefficients are zero -- large movements in the ex ante discount factors for future periods and therefore large movements in $L(\beta)$.

The suspected channel for spurious variation in $L(\beta)$ turns out not to be important. Table 3 presents $\tilde{\beta}_{t}$, various forecasted values of $\tilde{\beta}_{t}$, and $L(\beta)$ for the period 1973:1 to 1975:1. This period was characterized by large movements in $Z_{1 t}, \tilde{\beta}_{t}, \beta_{t}$ and $L(\beta)$. In particular, the series of sharp declines in the stock market from 1973:4 to 1974:3 are reflected in 1arge positive deviations in $Z_{1 t}$ and in the ex post return $\tilde{\beta}_{t}$. The positive deviations in $Z_{1 t}$ and $\tilde{\beta}_{t}$ generally lead to positive deviations in $\beta_{t}=E\left(\tilde{\beta}_{t} / t-1\right)$ for the following quarter. However, the impact of large realizations of $\widetilde{\beta}_{t}$ on expected discount factors 9 quarters ahead is very sma11. More importantly, the large positive realizations of $\tilde{\beta}_{t}$ in this period are not associated with large positive 
deviations of $L(\beta)$.

To make the point more generally, we observe that over the entire sample period, the correlation of the ex post rate of return, $\tilde{\beta}_{t-1}$, with the ex ante rate of return, $\beta_{t}$, is 0.46 and the correlation of $\tilde{\beta}_{t-1}$ and $L(\beta)_{t}$ is -0.06 . In addition, the correlation of $\beta_{t}$ and $L(\beta)_{t}$ is only 0.38 , indicating that high values of the one-period ex ante discount factor are only weakly associated with high values of $L(\beta)_{t}$.

\section{Standard Errors of Estimated $q$}

The calculated series $L(\beta), L(M)$ and linear q depend on the estimated coefficient matrix A. Except for an additive constant, each of these series can be written as

$$
\gamma c^{\prime} A(I-A \bar{\beta})^{-1} \tilde{Z}_{t}
$$

where $\gamma$ is a scalar constant, $c$ is a vector of known constants, and $Z_{t}=z_{t-1}-\bar{Z} \cdot \quad\left(\right.$ For $L(\beta), \gamma=\bar{l}(1-\bar{\beta})^{-1}, c=b ;$ for $L(I I), \gamma=\bar{\beta}, c=a$; for linear $\left.q, \gamma=1, c=\bar{M}(1-\bar{\beta})^{-1} b+\bar{\beta} a\right)$. As of the end of period $t-1$, the variable $Z_{t}$ in (21) is known. However, the parameter matrix $A$ is not known with certainty. Treating the non-trivial rows of matrix A as stochastic and using the covariance matrix of the estimated parameters of $A$, we can calculate the variance of the expression in (21). (See Appendix B). Thus we can compute the standard error of each our calculated values of $L(\beta), L(H)$ and 1 inear $q$. For the case in which $M=M^{\mathrm{u}}, \Omega=\Omega^{L}$ and $a=0.5$, we have computed the sample average of the standard errors of the estimated values for each of the three $q$ series reported in Table 4 . 


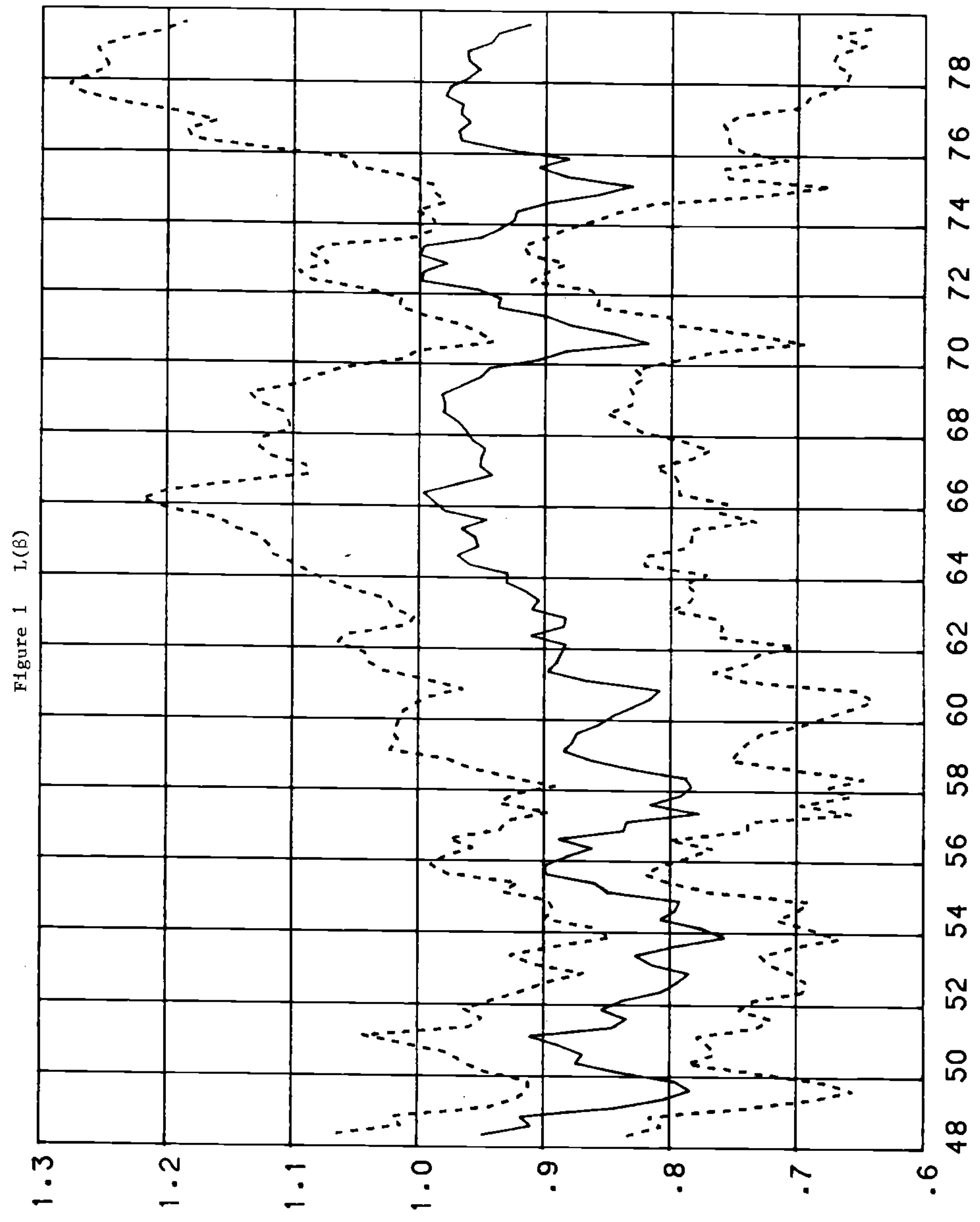




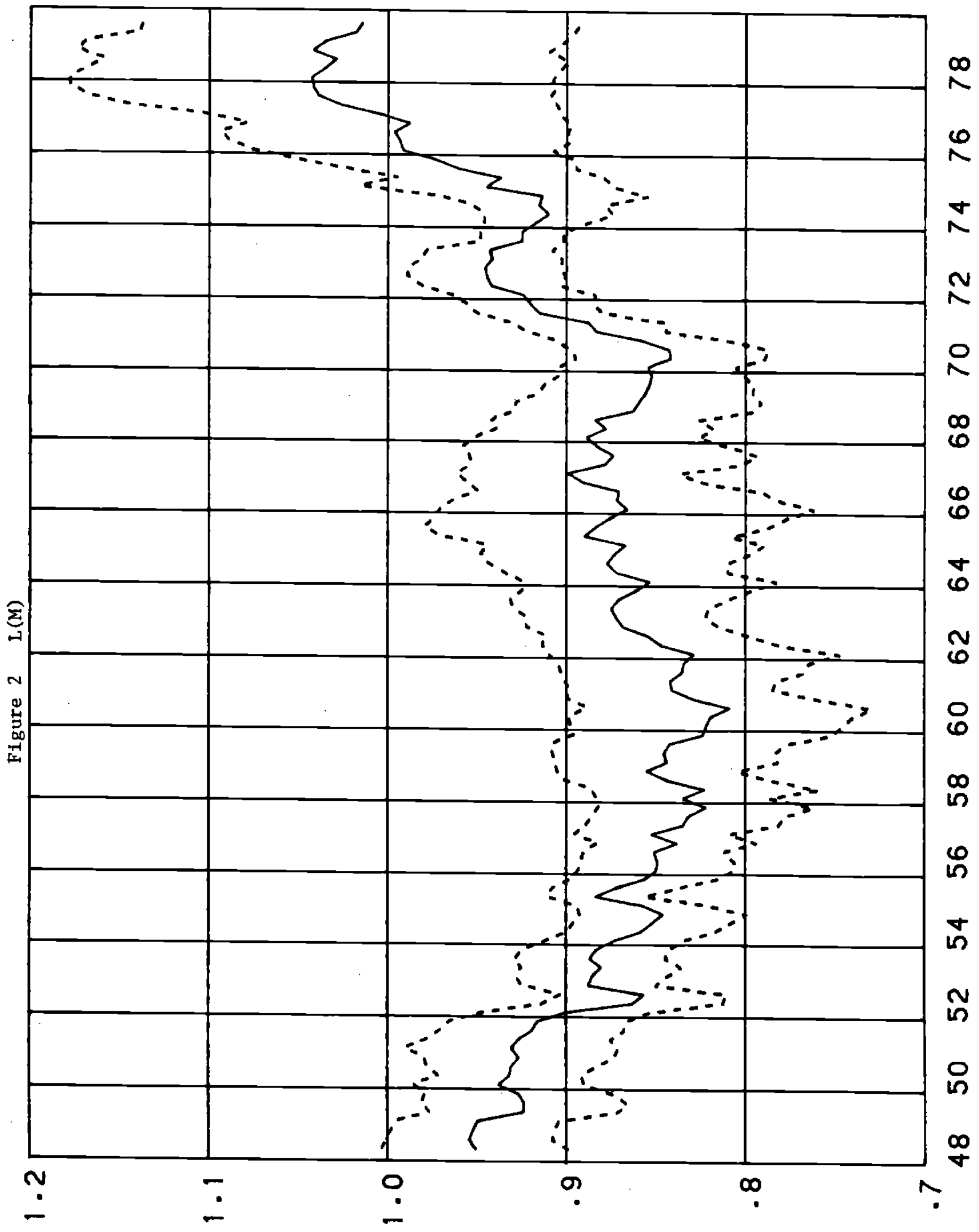




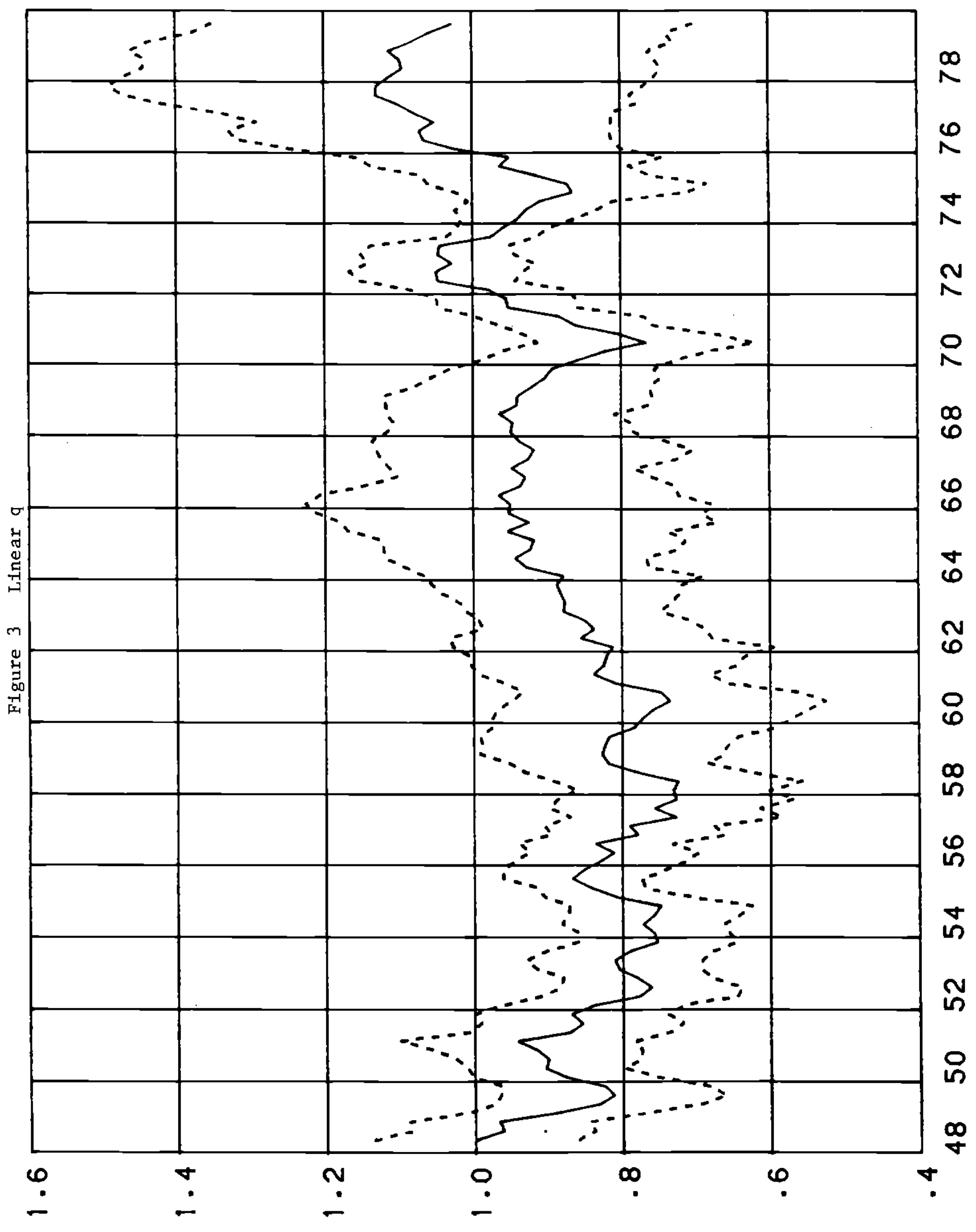


Table 4
q series
$L(\beta)$
$L(\mathrm{I})$
linear $q$
average standard error
0.070
0.031
0.083

In figures 1-3 we plot $q$ with the associated two standard error band for $q$ defined by $L(\beta)$, $L(M)$, and $l$ inear $q$, respectively. Observe that the standard error bands tend to widen somewhat at the end of the sample period.

VI. The a Series and Investment

The motivation for the construction and analysis of a series for marginal $q$ is that it should be the major determinant of the rate of investment. As explained earlier, equation (5a) implies that the optimal rate of investment is an increasing function of $q$. If in addition we assume that $\pi_{t}\left(K_{t}, I_{t}\right)$ is a linearly homogeneous function, then the optimal decision rule for investment can be expressed as a positive relationship between the investment capital ratio, $I_{t} / K_{t}$, and marginal $q_{t}$.

In Table 5 we present estinates ${ }^{4}$ of the following relation between $I_{t} / H_{t}$ and marginal q

$$
\begin{aligned}
I_{t} / K_{t} & =a(L)\left(\theta_{t} q_{t}\right)+\varepsilon_{t} \\
\varepsilon_{t} & =\rho(L) \varepsilon_{t-1}+\eta_{t}
\end{aligned}
$$

4. GLS estimates the following relation:

$$
(I / K)_{t}-\rho(L)(I / K)_{t-1}=a(L)(\theta q)_{t}-\rho(L)_{a}(L)(\theta q)_{t-1}+\eta_{t}
$$

If $q_{t}$ depended on current variables, two simultaneity problems could occur. $\eta_{f}$ could increase investment demand, aggregate demand and affect some of the determinants of $q_{t}$. $\eta_{t}$ would also, by increasing investment, increase capital later and thus could decrease anticipated marginal profits and $q_{t}$. These problems do not arise under our assumption that $q_{t}$ depends only on lagged variables. They do arise for most of the regressions which have been run using average $q$. 


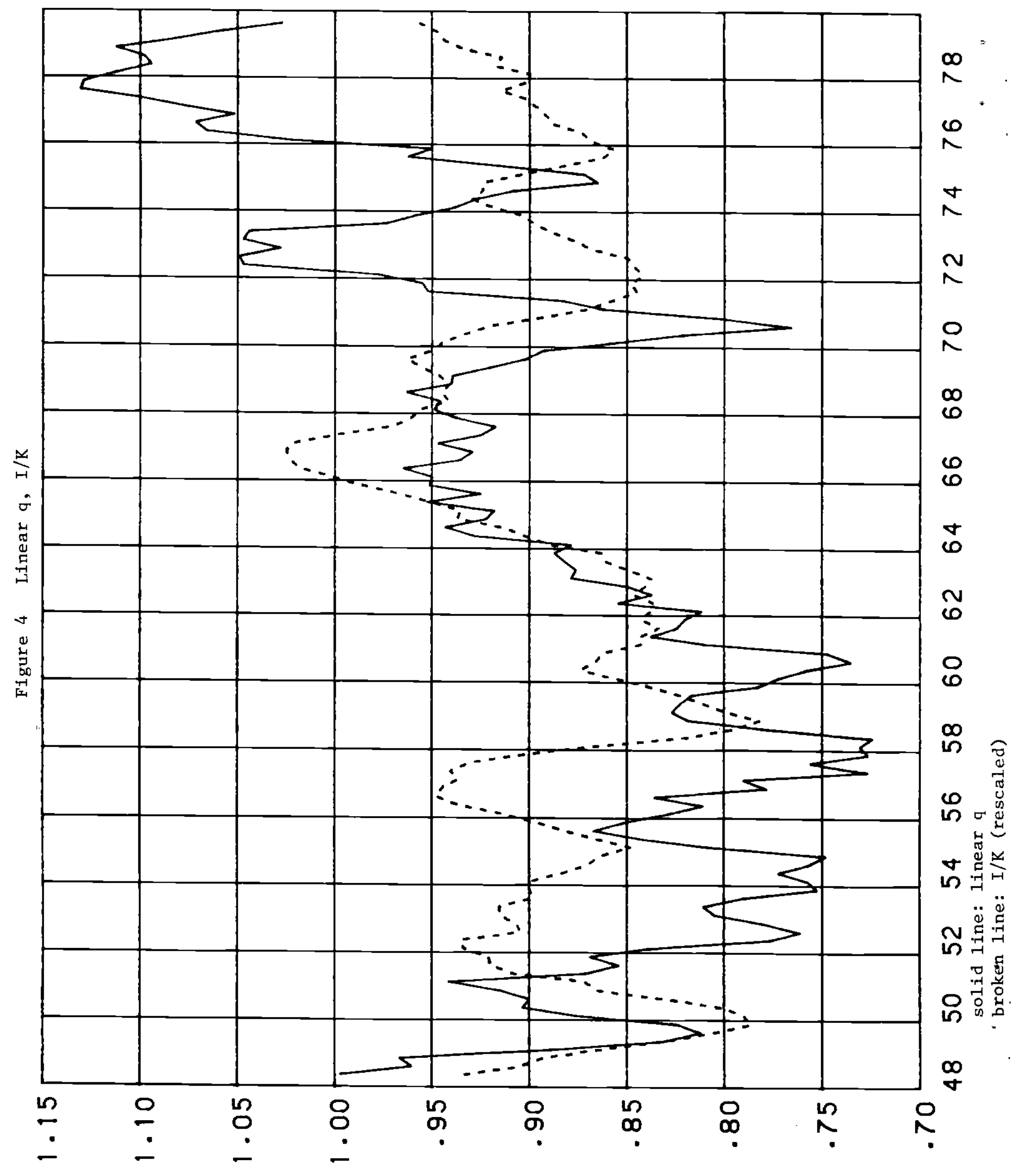


Table 5a

Regressions of $I / K$ on Tax-Adjusted $q$

$$
\Omega=\Omega^{L}
$$

RHS variables
$\theta q$
$(\theta q)_{-1}$
$(\theta q)_{-2}$
$z_{4,-1}$
$z_{4,-2}$
$z_{4,-3}$
$\left(z_{4}-z_{3}\right)_{-1}$
$\left(z_{4}-z_{3}\right)_{-2}$
$\left(z_{4}-z_{3}\right)_{-3}$
$\rho_{1}$
$\rho_{2}$
-2
$D W$
$R^{2}$

\begin{tabular}{|c|c|c|c|c|c|}
\hline \multicolumn{3}{|c|}{$\alpha=0.3$} & \multicolumn{2}{|c|}{$\alpha=0.5$} & \\
\hline $\begin{array}{c}-.0025 \\
(.0034) \\
.0080 \\
(.0038) \\
.0059 \\
(.0033)\end{array}$ & $\begin{array}{l}-.0051 \\
(.0034) \\
.0086 \\
(.0037) \\
.0059 \\
(.0034) \\
.304 \\
(.097) \\
.250 \\
(.096) \\
.151 \\
(.092)\end{array}$ & $\begin{array}{l}-.0029 \\
(.0033) \\
.0088 \\
(.0037) \\
.0054 \\
(.0033)\end{array}$ & $\begin{array}{c}-.0026 \\
(.0042) \\
.0105 \\
(.0047) \\
.0095 \\
(.0042)\end{array}$ & $\begin{array}{c}-.0062 \\
(.0042) \\
.0100 \\
(.0045) \\
.0085 \\
(.0043) \\
.286 \\
(.098) \\
.237 \\
(.095) \\
.148 \\
(.094)\end{array}$ & $\begin{array}{c}-.0038 \\
(.0041) \\
.0102 \\
(.0045) \\
.0078 \\
(.0041)\end{array}$ \\
\hline & & $\begin{array}{c}.595 \\
(.180) \\
.282 \\
(.172) \\
.237 \\
(.178)\end{array}$ & & & $\begin{array}{c}.562 \\
(.181) \\
.259 \\
(.171) \\
.242 \\
(.180)\end{array}$ \\
\hline $\begin{array}{l}1.59 \\
(.07) \\
-.66 \\
(.07)\end{array}$ & $\begin{array}{l}1.49 \\
(.08) \\
-.56 \\
(.08)\end{array}$ & $\begin{array}{l}1.57 \\
(.08) \\
-.63 \\
(.08)\end{array}$ & $\begin{array}{l}1.58 \\
(.07) \\
-.65 \\
(.07)\end{array}$ & $\begin{array}{l}1.48 \\
(.08) \\
-.56 \\
(.08)\end{array}$ & $\begin{array}{l}1.56 \\
(.08) \\
-.62 \\
(.08)\end{array}$ \\
\hline .96 & .96 & .96 & .96 & .96 & .96 \\
\hline 2.22 & 2.25 & 2.26 & 2.22 & 2.24 & 2.25 \\
\hline
\end{tabular}


Table 5b

Regressions of $\mathrm{I} / \mathrm{K}$ on Tax-Adjusted $\mathrm{q}$

$$
\begin{aligned}
& \Omega=\Omega^{S} \\
& \alpha=0.3
\end{aligned}
$$

RHS vạiables

$\theta \mathbf{q}$

$(\theta \mathrm{q})_{-1}$

$(\theta \mathrm{q})_{-2}$

$Z_{4,-1}$

$\mathrm{Z}_{4,-2}$

$\mathrm{Z}_{4,-3}$

$\left(\mathrm{z}_{4}-\mathrm{z}_{3}\right)-1$

$\left(\mathrm{z}_{4}-\mathrm{Z}_{3}\right)-2$

$\left(z_{4}-z_{3}\right)-3$

$\rho_{1}$

\section{$1.58 \quad 1.48$}

$(.07) \quad(.08)$

$-.65$

$-.56$

$(.07)$

$(.09)$

$.96 \quad .96$

$2.25 \quad 2.27$

.566

(.181)

.246

$(.174)$

.216

(.182)

1.56

$(.08)$

$-.62$

(.08)

.96

2.28

$$
\alpha=0.5
$$

$\begin{array}{lll}.0000 & -.0035 & -.0013 \\ (.0039) & (.0040) & (.0039) \\ .0109 & .0097 & .0103 \\ (.0045) & (.0044) & (.0043) \\ .0089 & .0082 & .0077 \\ (.0039) & (.0040) & (.0038) \\ & .271 & \\ & (.098) & \\ & .221 & \\ & (.097) & \\ & .133 & \\ & (.096) & \end{array}$

.560

(.182)

.233

(.173)

.215

(.182)

$\begin{array}{lll}1.58 & 1.49 & 1.56\end{array}$

$(.07) \quad(.08) \quad(.08)$

$\begin{array}{lll}-.65 & -.56 & -.62\end{array}$

$\begin{array}{lll}(.07) & (.08) \quad(.08)\end{array}$

$\begin{array}{lll}.96 & .96 & .96\end{array}$

$\begin{array}{lll}2.24 & 2.26 & 2.27\end{array}$ 
where $\theta_{t}$ is the tax-adjusted price of capita $1^{5}$ which depends on the investment tax credit, the present value of depreciation deductions and the price of capital; $a(L)$ and $\rho(L)$ are distributed lag operators. The specification in (22) differs from the investment rule in (5a) in three ways: (1) we have included the tax factor $\theta_{t}$ which recognizes that the investment tax credit and depreciation deductions reduce the effective price of new capital goods; (2) we have allowed for the disturbance term $\varepsilon_{t}$ to be serially correlated: (3) we have included lagged values of $\theta q$ on the right hand side. One should not interpret the lagged values of $\theta q$ as representing the effects of delivery lags. Ilowever, we included lagged values $q_{t-i}$ to make our investment specification comparable to specifications using current and lagged values of market-valuebased average $q$. Thus, these regressions should not be viewed as structural relations but rather as a convenient way of examining sample correlations.

The first and fourth colums of Tables $5 a$ and $5 b$ present the regressions of $I / K$ on current and lagged $q_{t}$ for various information sets $\left(\Omega^{L}, \Omega^{S}\right)$ and values of a $(0.3,0.5)$. These 4 columns all lead to the same results. Although the contemporaneous value of $q_{t}$ is not a significant explanator of investment, both $q_{t-1}$ and $q_{t-2}$ tend to have significant positive effects on $I_{t} / F_{t}$. In all cases, the various $q$ variables leave unexplained a large and serially correlated residual which is fairly well approximated by a secondorder autoregressive process. Finally, the implied elasticities of $I / K$ with respect to current and 1 agged $q$ are roughly 0.1 to 0.3 .

5. $\theta_{t}$ is defined as $\left[\left(1-k_{t}-\tau_{t} Z_{t}\right) P_{K t} / P_{m t}\right]^{-1}$ where $k_{t}$ is the investment tax credit, $\tau_{t}$ is the corporate income tax rate and $z_{t}$ is the present value of depreciation deductions. $Z$ is constructed under static expectations; constructing it under rational expectations did not appear worth the effort. The last data available for $\theta$ are for $1976: 4$ and this has determined our sample period for the regressions in Table 5 . 
The results of regressing $I / K$ on our constructed series for marginal $q$ are remarkably similar to the results obtained using average q measures based on asset market valuation of firms. The fact that both types of measures of q. which are constructed in very different maners, leave large serially correlated residuals in investment suggests that there may be other important factors which are not captured by $q$. We chose to consider the output/capital ratio (measured by $Z_{4}$ ) and profit per unit of capital (measured by $Z_{4}-Z_{3}$ ).

Tables $5 a$ and $5 b$ present the regressions in which lagged values of $z_{4}$ and $\left(z_{4}-z_{3}\right)$ are added to the specification in (22). To avoid obvious simultaneity problems, and because $q_{t}$ depends only on lagged variables, we did not include current values of $z_{4}$ or $\left(z_{4}-z_{3}\right)$. Again, we note that these regressions are not structural equations but are merely a convenient form in which to present sample correlations. We find that in all cases, the output or profit variable is significant. That is, it appears that output or profit has an effect on investment beyond any effects which work through marginal q.

We return now to the question of delivery lags and the lagged expectations of q. If a type of capital requires n periods for delivery, then investment orders at time $t$ would depend on $E\left(q^{*}{ }_{t+n} l_{t-1}\right)$. Investment expenditures at time $t$ would depend on investment orders from time $t-n$ to $t$, and thus on $E\left(q_{t+n-i}^{*} \Omega_{t-1-i}\right), i=0, \ldots, n$, not on $q_{t-i} \equiv E\left(q_{t-i}^{*} \mid \Omega_{t-i-1}\right)$.

The calculation of $E\left[q_{t}^{*} \mid \Omega_{t-n}\right]$ is particularly simple for $q$ measured by $L(\beta), L(M)$ or linear $q$. Since each of the three series can be written in the form presented in (21) and since $E\left(\tilde{Z}_{t} \mid \Omega_{t-n}\right)=E\left(Z_{t-1}-\bar{Z} \mid \Omega_{t-n}\right)=A^{n-1}\left(Z_{t-n}-\bar{Z}\right)$, we obtain

$$
E\left(q_{t}^{*} \mid \Omega_{t-n}\right)=\gamma c^{\cdot}(I-\bar{A} \beta)^{-1} A^{n}\left(Z_{t-n}-\bar{Z}\right)
$$


where $\gamma$ and $c$ are the scalar and vector constants described below equation (21). We have calculated these lagged expectations of a and have regressed $I / K$ on them. However, these lagged expectations of q proved much less successful than lagged values of $q$ : $E\left(q^{*} \mid \Omega_{t-1}\right)$ generally had a negative and of ten significant coefficient; $E\left(q_{t}^{*} \mid \Omega_{t-2}\right)$ and $E\left(q_{t}^{*} \mid \Omega_{t-3}\right)$ generally had positive but insignificant coefficients. Further research is required in order to combine the q theory and delivery lags in an empirically satisfactory maner.

\section{Concluding Remarks}

The research reported in this paper can be divided into two parts: first we calculated and analyzed the properties of series for marginal q calculated under a variety of assumptions; then we examined the relation between investment and our various q series. The major finding of the first part of the paper is that more than half of tho wyclical variation (as measured by the standare devidion) of marginal $q$ is accouted for by variation in the ex ante cost of capital. This finding appears to be rather robust: it holds for each of our 12 sets of assurptions which are based on alternative information sets, alternative measures of the marginal profitability of capital and alternative shares of equity in total financing. As explained earlier, this finding that variation in discount factors accounts for a substantial fraction of the variation in a present value series has implications for the variability of asset prices in general.

Although the first part of the paper succeded in finding a large contribution of cost of capital variability to the cyclical variability of $q$, the link between investment and the cyclical behavior of the cost of capital is more tenuous because of the relatively poor performance of $q$ in explaining 
$-25-$

investment. There is a long 1 is of potential culprits. The first is aggiegation problems. The second is the specification of technology and the assumption of homogeneity of capital. The third is the assumption of perfect financial markets and the absence of "liquidity constraints" for firms. Prosecution and indictments are left for future research. 
Appendix A. Second Order Approximation to $q$

Collecting the assumptions from the text, we have:

$$
\begin{aligned}
& Q_{t}=E\left(\sum_{j=0}\left(\prod_{i=0}^{1} B_{t+1}\right) M_{t+j}\right) \\
& \left(z_{t}-\bar{z}\right)-A\left(z_{t-1}-\bar{z}\right)+\varepsilon_{t} ; E\left(\varepsilon_{t}\right)=0 \\
& E\left(\varepsilon_{t} c_{t}^{\prime}\right)=0 \text { if } t+5 \\
& \text { - I } 1 f \quad t=s \\
& B_{t}=b^{\prime} E\left(Z_{t}\right) \quad ; \quad H_{t}=a^{\prime} Z_{t} \\
& E(\cdot) \equiv E\left(\cdot \mid \Omega_{t-1}\right) \quad ; \quad \Omega_{t-1}-\left(\varepsilon_{t-1}, E_{t-2}, \cdots\right)
\end{aligned}
$$

9. B, M are scalar random variables

$2, c$ are $(n \times 1)$ vector randon variables.

a. $b, A$ are $(n \times 1),(n \times 1)$ and $(n \times n)$ respectively.

Define ex post $q_{t}$, q as $\sum_{t=0}^{*}\left(\prod_{1=0}^{j} B_{t+1}\right)_{t+j}$. (Nove that $B_{t+1}$ is not the realized value of the ex post rate in perfod $t+1$ but the value of the ex ante rate in period $t+1$.$) Take a quadratic approximation to q around$ $B_{t+1}-\bar{B} V_{1}$ and $M_{t+j}-\bar{M} \forall_{j}$, where $\bar{B}$ and $\bar{M}$ are the woonditional means of $\varepsilon$ and $X$, and take expectations condition on $\Omega_{t-1}$. Th1s gives:

$$
q_{t}=\bar{q}+I(B)+I(M)+Q(B, B)+Q(M, M)+Q(B, M)
$$

We define and consider each of these elemepts in turn: 
(1)

$$
\bar{Q} \equiv \sum_{\mathcal{I}=0} \bar{B}^{j+1} \bar{M}=\bar{B}(1-\bar{B})^{-1} \bar{M}
$$

(2)

$$
I(B) \equiv \sum_{1=0} \delta q_{t}^{*} / \delta B_{t+1} E\left(B_{t+1}-\bar{B}\right)
$$$$
\delta q^{*}{ }_{t} / \delta B_{t+1}=\sum_{j=1}\left(\sum_{\substack{l=0 \\ l \neq 1}}^{1} \bar{B}_{t+2}\right)_{\bar{H}+j}=\bar{M}(1-\bar{B})^{-1} \bar{B}^{-1}
$$$$
L(B)=\bar{M}(1-\bar{B})^{-1} \sum_{1=0} \bar{B}^{-1} E\left(B_{t+1}-\bar{B}\right)
$$$$
\text { - }(1-\bar{B})^{-1} \bar{M} \sum_{1=0} \bar{B}^{-1} b^{\prime} A^{1+1}(z t-1-\bar{z})
$$$$
=(1-\bar{B})^{-1} \bar{Z}^{\prime} a b^{\prime} A\left(I-A_{\bar{B}}\right)^{-1}\left(z_{t-1}-\bar{z}\right)
$$

(3)

$$
L(M) \equiv \sum_{1=0} \delta q^{*}{ }_{t} / \delta M_{t+1} E\left(M_{t+1}-\bar{M}\right)
$$

$$
\begin{aligned}
\delta q^{*}{ }_{t} \delta M_{t+1} & =\prod_{l=0}^{1} \bar{B}_{t+l}-\bar{B}^{-1+1} \\
L(M) & =\sum_{1=0} \bar{B}^{-1+1} E\left(M_{t+1}-\bar{M}\right) \\
& =\sum_{1=0}^{\infty} \bar{B}^{-1+1} a^{\prime} A^{1+1}\left(Z_{t-1}-\bar{Z}\right)=A^{\prime} A^{\bar{B}}(I-A \bar{B})^{-1}\left(Z_{t-1}-\bar{Z}\right)
\end{aligned}
$$


(4)

$$
\begin{aligned}
& Q(B, B) \equiv \sum_{1=0} \sum_{j=0} \frac{1}{2} \delta^{2} q_{t}^{\star} / \delta B_{t+1} \delta B_{t+j} E\left(B_{t+1}-\bar{B}\right)\left(B_{t+j}-\bar{B}\right) \\
& \delta^{2} q_{t}^{*} / 6 B_{t+1} 8 B_{t+j}=0 \\
& =\sum_{k=\max (1,1)}^{\infty}\left(\prod_{\substack{k=0 \\
l \neq 1, j}}^{k} \bar{B}_{t+l}\right)_{t+k} \\
& \text { - } \overline{\mathrm{Z}}(1-\bar{B})^{-1} \overline{\bar{B}}(\max (1, j)-1) \\
& 1 f 1+j \rightarrow \\
& Q(B, B)=\bar{H}(1-\bar{B})-1 \sum_{1=0}^{\infty} \sum_{j=1+1} \bar{B}^{j-1} E\left(B_{t+1}-\bar{B}\right)\left(B_{t+j}-\bar{B}\right)
\end{aligned}
$$

Cons1der $E\left(B_{t+1}-\bar{B}\right)\left(B_{t+j}-\bar{B}\right)$. It is equal to:

$$
\begin{aligned}
& E\left(b^{\prime}\left(A^{1+1}\left(z_{t-1}-\bar{z}\right)+\cdots+A_{t+1-1}\right)\left(\left(z_{t-1}-\bar{z}\right)^{\prime} A^{\prime} j+1+\cdots+\varepsilon_{t+j-1^{\prime}}^{\prime}\right) b\right)= \\
& E\left(b^{\prime}\left(A^{1+1}\left(z_{t-1}-\bar{z}\right)+\cdots+\varepsilon_{t+1}\right)\left(\left(z_{t-1}-\bar{z}\right)^{\prime} A^{\prime j+1}+\cdots+\varepsilon_{t+j}^{\prime}\right) b-\right. \\
& E\left(b^{\prime} \varepsilon_{t+1}\left(\left(z_{t-1}-\bar{z}\right) A^{\prime j+1}+\cdots+\varepsilon_{t+j}^{\prime}\right) b\right)- \\
& E\left(b^{\prime}\left(A^{1+1}\left(z_{t-1}-\bar{z}\right)+\cdots+\varepsilon_{t+1}\right) \varepsilon_{t+j}^{\prime} b\right)
\end{aligned}
$$

Not1ng that $E\left(\varepsilon_{t+j}\left(z_{t-1}-\bar{z}\right)^{\prime}\right)-0 V_{j} \geq 0$ and $E\left(\varepsilon_{t+j^{\prime}+1}^{\prime}\right)=0 V_{j}+j$,

$$
\begin{aligned}
& Q(B, B)=\bar{M}(1-\bar{B})^{-1}\left\{J_{1}+J_{2}+J_{3}\right\} \text { where: } \\
& J 1 \equiv \sum_{1=0}^{0} \sum_{j=1+1} \bar{B}^{j-1}\left(z_{t-1}-\bar{z}\right) \cdot A^{1+1} b b^{\prime} A^{j+1}\left(z_{t-1}-\bar{z}\right)
\end{aligned}
$$




$$
J 2 \equiv b^{\prime} \sum_{1=0}^{\infty} \sum_{j=1+1} \bar{B}^{j-1} \sum_{i=0}^{1} A^{2} \Sigma A^{j-1+2} b
$$

Consider J1. It can be rewritten as:

$$
\begin{aligned}
J 1 & =\bar{B}^{-2}\left(z_{t-1}-\bar{Z}\right) \cdot \sum_{1=0} A^{1+1} b b^{\prime} \sum_{j-1+1}^{\infty} A^{j+1} \bar{B}^{j+1}\left(z_{t-1}-\bar{Z}\right) \\
& =\bar{B}^{-2}\left(z_{t-1}-\bar{Z}\right) \cdot \sum_{1=0} A^{1+1} b b^{\prime}(A \bar{B})^{1+2}(I-A \bar{B})^{-1}\left(z_{t-1}-\bar{Z}\right)
\end{aligned}
$$

Decompose $A$ as $A=P A P^{-1}$ where $\Lambda$ is a diagonal matrix containing the eigenvalues of A. Replacing above gives:

$$
J 1=\bar{B}^{-2}\left(z_{t-1}-\bar{Z}\right) \cdot P^{-1},\left[\sum_{1=0}^{\infty} \Lambda^{1+1} P^{\prime} b b^{\prime} P(\Lambda \bar{B})^{1+2}\right] P^{-1}(I-A \bar{B})^{-1}\left(z_{t-1}-\bar{Z}\right)
$$

Define $D \equiv P^{\prime} b b^{\prime} P=\left(d_{1 j}\right)_{1, j}$ and $S 1$ as the matrix in brackets in the expression for $31, S 1=\left(S 1_{1 j}\right)_{1, j}$. Note that:

$$
\begin{aligned}
& S 1_{11}=d_{1 f} \lambda_{1} \lambda_{j}^{2} \bar{B}^{-2}\left(1-\lambda_{1} \lambda_{j} \bar{B}\right)^{-1} \text { and } \\
& J 1=\bar{B}^{-2}\left(z_{t-1}-\bar{Z}\right) \cdot P^{-1} \cdot(S 1) P^{-1}(I-A \bar{B})^{-1}\left(z_{t-1}-\bar{Z}\right)
\end{aligned}
$$




\section{A-5}

Cons1der J2. It can be rewr1ttea as:

$$
\begin{aligned}
& J 2=b^{0} \sum_{2=0}^{\infty} \sum_{1-2} \sum_{j=1+1} \bar{B}^{j-1} A^{2} \Sigma A^{j-1+2} b \\
& =b^{0} \sum_{l=0}^{\infty} \sum_{1=l} A^{2} \Sigma A^{2+1} \bar{B}^{1}\left(I-A^{\prime} \bar{B}\right)^{-1} b \text {. } \\
& =(1-\bar{B})^{-1} b^{\prime} \sum_{l=0}^{\infty}\left(A_{\bar{B}}\right)^{2} \Sigma A^{\prime 2+1}\left(I-A^{\prime} \bar{B}\right)^{-1} b
\end{aligned}
$$

Decooposing $A$ as $P \wedge P^{-1}$ and replacing above glves:

$$
J 2=(1-\bar{B})^{-1} b^{\prime} P\left[\sum_{l=0}^{\infty}(\Lambda \bar{B})^{2} P^{-1} \sum P^{-1} \cdot \Lambda^{2+1}\right] P^{\prime}\left(I-A^{\prime} \bar{B}\right)^{-1} b
$$

Define $E \equiv\left(P^{-1} \sum P^{-1}\right)=\left(F_{1 f}\right)_{1, j}$ and $S 2$ as the matrix 1a brackets in the expression for $J 2,52-\left(52_{1 j}\right)_{1, j}$. Note that:

$$
\begin{aligned}
& s 2_{1 j}=F_{1 f^{j}} \lambda_{j}\left(1-\lambda_{1} \lambda_{f} \bar{B}\right)^{-1} \text { and } \\
& J 2=(1-\bar{B})^{-1} b^{\prime} P(S 2) P^{\prime}\left(I-A^{\prime} \bar{B}\right)^{-1} b
\end{aligned}
$$

Consider J3. It can be reviteten as: 


$$
\begin{aligned}
J 3 & =-b^{\prime} \bar{B}^{-1} \sum_{1=0}^{\bar{B}} \bar{B}^{-1} \sum_{j=1+1}^{\infty} \sum\left(B A^{\prime}\right)^{j-1} b \\
& =-b^{\prime}(1-\bar{B})^{-1} \Sigma A^{\prime}\left(I-\bar{B} A^{\prime}\right)^{-1} b
\end{aligned}
$$

(5)

$$
Q(M, M) \equiv \sum_{1=0} \sum_{j=0} \frac{1}{2} \delta^{2} q^{\star}{ }_{t} / \delta M_{t+1} \delta M_{t+j} E\left(M_{t+1}-\bar{M}\right)\left(M_{t+j}-\bar{M}\right)
$$

$$
\begin{aligned}
& \delta^{2} q_{t}{ }_{t} / \delta M_{t+1} \delta M_{t+j}=0 \quad v_{1, J} \\
& Q(M, M)=0 \\
& Q(B, M)=\sum_{1=0} \sum_{j=0} \delta^{2} q_{t}^{*} / \delta B_{t+1} \delta M_{t+j} E\left(B_{t+1}-\bar{B}\right)\left(M_{t+j}-\bar{M}\right)
\end{aligned}
$$

(6)

$$
\begin{aligned}
& \delta^{2} q_{t}^{k} / \delta B_{t+j} \delta M_{t+j}=\bar{B}^{j} \quad \text { If } \quad 1 \leq 1,0 \text { 1f } 1>j \\
& Q(B, M)=\sum_{1=0} \sum_{j=1} \bar{B}^{-j} E\left(B_{t+1}-\bar{B}\right)\left(M_{t+j}-\bar{Y}\right)
\end{aligned}
$$

Consider $E\left(B_{t+1}-\bar{B}\right)\left(M_{t+j}-\bar{M}\right)$. It 1s equal to:

$$
\begin{aligned}
\left.E\left(b^{\prime}\left(A^{1+1}\left(z_{t-1}-\bar{z}\right)+A^{1} \varepsilon_{t}+\cdots+A \varepsilon_{t+1-1}\right)\right)\left(\left(z_{t-1}-\bar{z}\right) A^{\prime} j^{j+1}+\cdots+\varepsilon_{t+j^{\prime}}^{\prime} A^{\prime}\right) a\right) \\
=E\left(b^{\prime}\left(A^{1+1}\left(z_{t-1}-\bar{z}\right)+\cdots+\varepsilon_{t+1}\right)\left(\left(z_{t-1}-\bar{z}\right) A^{\prime} j+1+\cdots+\varepsilon_{t+j}^{\prime} A^{\prime}\right) a\right) \\
-E\left(b^{\prime} c_{t+1}\left(\left(z_{t-1}-\bar{z}\right)^{\prime} A^{\prime j+1}+\cdots+\varepsilon_{t+j}^{\prime} A^{\prime}\right) a\right)
\end{aligned}
$$

Not1ng that $\left.\varepsilon_{\left(\varepsilon_{t+j}\right.}\left(z_{t-1}-\bar{z}\right)^{\prime}\right)=0 \quad \forall_{j} \geq 0, \varepsilon\left(\varepsilon_{t+j^{\prime}} \varepsilon_{t+1}^{\prime}\right)=0 \quad v_{1} \neq j$, 


$$
Q(B, M)=\mathrm{H} 1+\mathrm{B2}+\mathrm{H3}
$$

where

$$
\begin{aligned}
& \text { B1 } \equiv\left(z_{t-1}-\bar{z}\right)^{\prime} \sum_{1=0}^{\infty} \sum_{j=1}^{\infty} A^{1+1} b a^{\prime} A^{j+1} \bar{B}^{j}\left(z_{t-1}-\bar{z}\right) \\
& \text { B2 } \equiv b^{\prime} \sum_{1=0} \sum_{j=1}^{\infty} \bar{B}^{j} \sum_{l=0}^{1} A^{2} \Sigma A^{j-1+l} a . \\
& \text { B3 } \equiv-b^{\prime} \sum_{1=0}^{\infty} \sum_{j=1}^{\infty} \bar{B}^{-j} \sum A^{j-1} a
\end{aligned}
$$

Consider El. It can be rewriteen as:

$$
\begin{aligned}
\text { Bl } & =\left(z_{t-1}-\bar{Z}\right)^{\prime} \sum_{1=0} A^{1+1} b a^{\prime} A^{1+1} \bar{B}^{-1}(I-A \bar{B})^{-1}\left(Z_{t-1}-\bar{Z}\right) \\
& =\left(z_{t-1}-\bar{Z}\right) \cdot P^{-1} \cdot\left[\sum_{1=0} \Lambda^{1+1} P^{\prime} b a^{\prime} P \Lambda^{1+1} \bar{B}^{-1}\right] P^{-1}(I-A \bar{B})^{-1}\left(Z_{t-1}-\bar{Z}\right)
\end{aligned}
$$

Define $G=\left(P^{\prime} b^{\prime} P\right)=\left(G_{1 j}\right)_{1, j}$ and $\nabla$ as the matrix in brackets io the expression for $\mathrm{Bl}$ above. Note that:

$$
\begin{aligned}
& \nabla_{1 j}=G_{1 j} \lambda_{1} \lambda_{j}\left(1-\lambda_{1} \lambda_{j} \bar{B}\right)^{-1} \text { and } \\
& \Delta 1=\left(z_{t-1}-\bar{z}\right) \cdot p^{-1} \cdot p^{-1}(I-\lambda \bar{B})^{-1}\left(z_{t-1}-\bar{z}\right)
\end{aligned}
$$


Consider H2. It can be rewritien as:

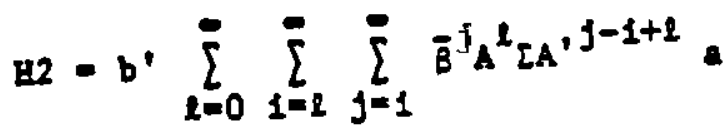

$$
\begin{aligned}
& -b \sum_{l=0} \sum_{i=1} A^{l} L A^{\prime 2} \bar{B}^{-1}\left(I-A^{\prime} \bar{B}\right)^{-1}= \\
& =(1-\bar{B})^{-1} b^{\prime} \sum_{l=0} A^{l} \sum A^{l} \bar{B}^{-l}\left(I-A^{\prime} \bar{B}\right)^{-1} a \\
& =(1-\bar{B})^{-1} b^{\prime} P\left[\sum_{\ell=0} \Lambda^{2} P^{-1} \sum P^{-1}(\Lambda \bar{B})^{l}\right] P^{\prime}\left(I-A^{\prime} \beta\right)^{-1} a
\end{aligned}
$$

Recall the definition of $F$ above and define $I$ as the matrix in brackets in the expression for 12 :

$$
\begin{aligned}
& I_{11}=F_{1 f}\left(1-\lambda_{1} \lambda_{f} \bar{B}\right)^{-1} \text { and } \\
& \text { H2 }=(1-\bar{B})^{-1} b^{\prime} P T P^{\prime}\left(I-A^{\prime} \bar{B}\right)^{-1} \text { a }
\end{aligned}
$$

Consider H3. It can be rewriten as: 
A-9

$$
\begin{gathered}
83--b^{\prime} \Sigma \sum_{1=0}^{\infty} \bar{B}^{-1} \sum_{j=1}^{\infty}\left(\bar{B} A^{\prime}\right)^{j-1} a \\
=-b^{\prime}(1-\bar{B})^{-1} \sum\left(I-\bar{B} A^{\prime}\right)^{-1} a
\end{gathered}
$$

Collecting all terms allows compucation of the guadratic approximation. 
Appendix 3

Suppose that $y_{t}$ can be written as

$$
y_{t}=g\left(A^{*}\right) \tilde{z}_{t}
$$

where $\tilde{Z}_{t}$ is a column vector of length $\mathrm{kL}$ and $\mathrm{g}\left(A^{*}\right)$ is a row vector of the same length ( $k$ is the number of variables in the VAR's, 5 or 7 ; $L$ is the number of 1ags, 4). Let $A^{*}$ be the column vector of 1 ength $k^{2} L$ obtained from the $k I, k L$ matrix A in (9) by stacking the transposes of the kestimated $r$ ows of A. Observe that the covariance matrix of $A^{*}$ is $\Sigma \otimes\left(Z^{0} Z^{0}\right)^{-1}$ where $\Sigma$ is the kxk matrix defined in (9) and $z^{0}$ is the data natrix with $i$ th row equal to $\tilde{Z}_{t}$. Finally, suppose that $g\left(A^{*}\right)=\gamma c^{\prime} A\left(I-A_{\hat{\beta}}\right)^{-1}$ where $\gamma$ is a scalar constant and $c^{\prime}$ is a row vector of known constants. Observe that

$$
\frac{\partial g(A *)}{\partial x}=\gamma c^{\prime}\left[\frac{\partial \Lambda}{\partial x}(I-A \Gamma)^{-1}+A \frac{\partial}{\partial x}(I-A \bar{\Gamma})^{-1}\right]
$$

Recall that in general $\frac{\partial G^{-1}}{\partial x}=-G^{-1} \frac{\partial G}{\partial x} G^{-1}$ where $G$ is an invertible matrix. Therefore,

$$
\frac{\partial(I-A \bar{B})^{-1}}{\partial x}=\bar{P}(I-A \bar{C})^{-1} \frac{\partial A}{\partial x}(I-A \bar{P})^{-1}
$$

Substituting (B-3) into (I-2) yie1ds

$$
\frac{\partial g\left(A^{*}\right)}{\partial x}=\gamma c^{\prime}(I-A \bar{\beta})^{-1} \frac{\partial A}{\partial x}(I-A \bar{\beta})^{-1}
$$

Observe that $\frac{\partial A}{\partial a_{i j}}=e_{i} e^{\prime}{ }_{j}$ where $e_{i}$ and $e^{\prime} j_{j}$ are the $i$ th colum and $j$ th row, respectively, of the identity matrix. Therefore,

$$
\frac{\partial g\left(A^{*}\right)}{\partial a_{i j}}=\gamma c^{\prime}(I-A \bar{\beta})^{-1} e_{i} e^{\prime}(I-A \beta)^{-1}
$$

Letting 


$$
\frac{\partial g\left(A^{*}\right)}{\partial A^{*}}=\left[\frac{\partial g\left(A^{*}\right)}{\partial a_{1,1}}, \ldots \frac{\partial g\left(A^{*}\right)}{\partial a_{1, k L}}, \frac{\partial g\left(A^{*}\right)}{\partial a_{2,1}}, \ldots \frac{\partial g\left(A^{*}\right)}{\partial a_{k, k L}}\right]
$$

we obtain

$$
\frac{\partial g\left(A^{*}\right)}{\partial A^{*}}=\gamma\left(\left[I_{k} \vdots 0\right]\left(I-A_{\bar{\beta}}\right)^{-1} c\right) \otimes(I-A \bar{\beta})^{-1}
$$

where $I_{k}$ is the kxk identity matrix.

Now observe that the variance of $y_{t}$, given $\tilde{z}_{t}$, is equal to $\tilde{Z}_{t} \cdot \frac{\partial g}{\partial A^{*}} \cdot \operatorname{Var}\left(A^{*}\right) \frac{\partial g}{\partial \Lambda^{*}} \tilde{Z}_{t}$. Using this fact along with (B-6) and the variance of $\Lambda^{*}$ we obtain

$$
\begin{aligned}
& \operatorname{var}\left(y_{t} \mid \tilde{z}_{t}\right)=\gamma^{2} c^{\prime}(I-A \bar{\beta})-1\left[\begin{array}{ccc}
\overline{2} & 0 \\
\hdashline & 0 \\
0 & \vdots & 0
\end{array}\right]\left(I-A_{\bar{p}}\right)^{-1}{ }_{c} \\
& x \tilde{z}_{t}^{\prime}(I-A \bar{\beta})^{-1}\left(Z^{0} z^{0}\right)^{-1}(I-A \bar{\rho})^{-1} \tilde{z}_{t}
\end{aligned}
$$




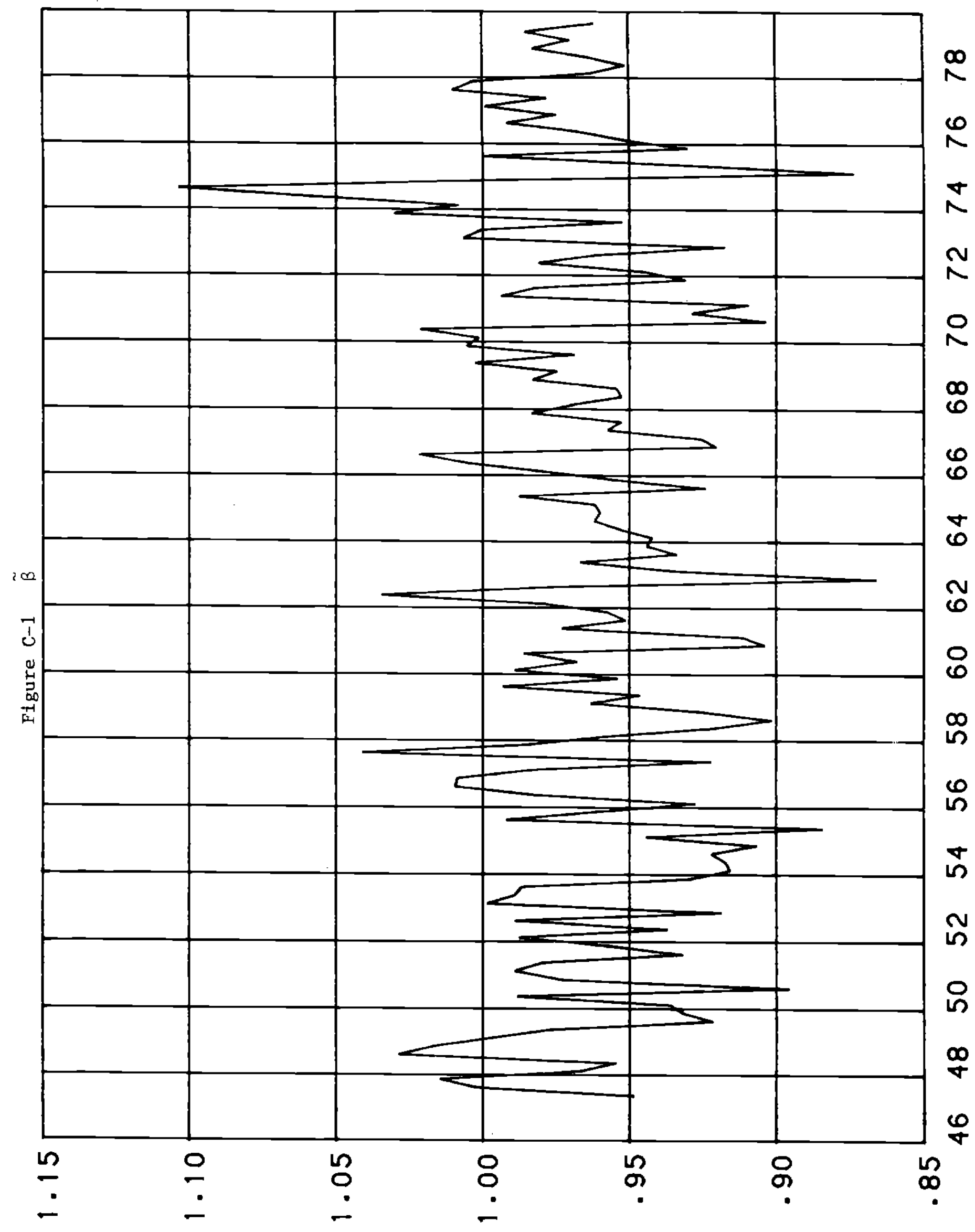




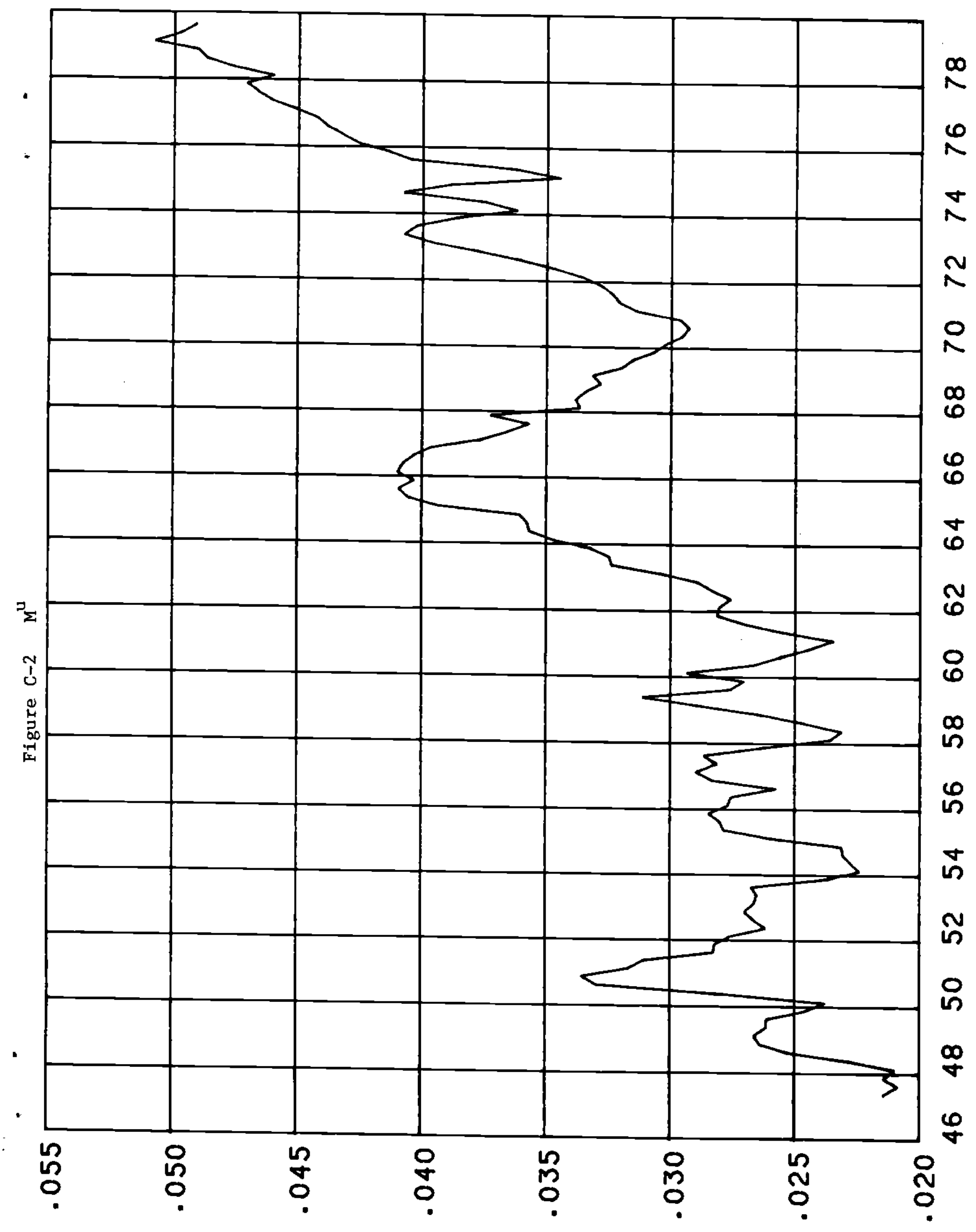




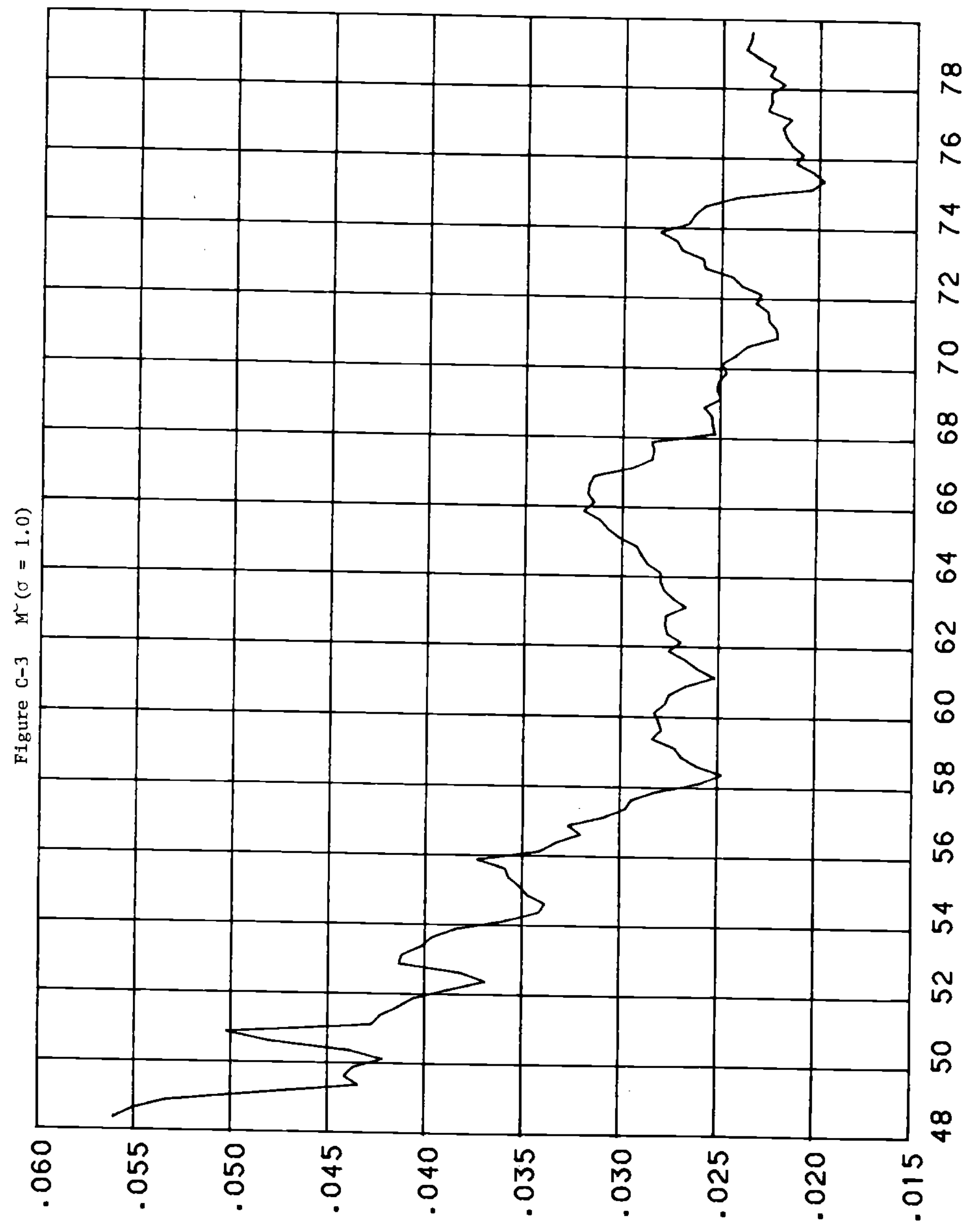




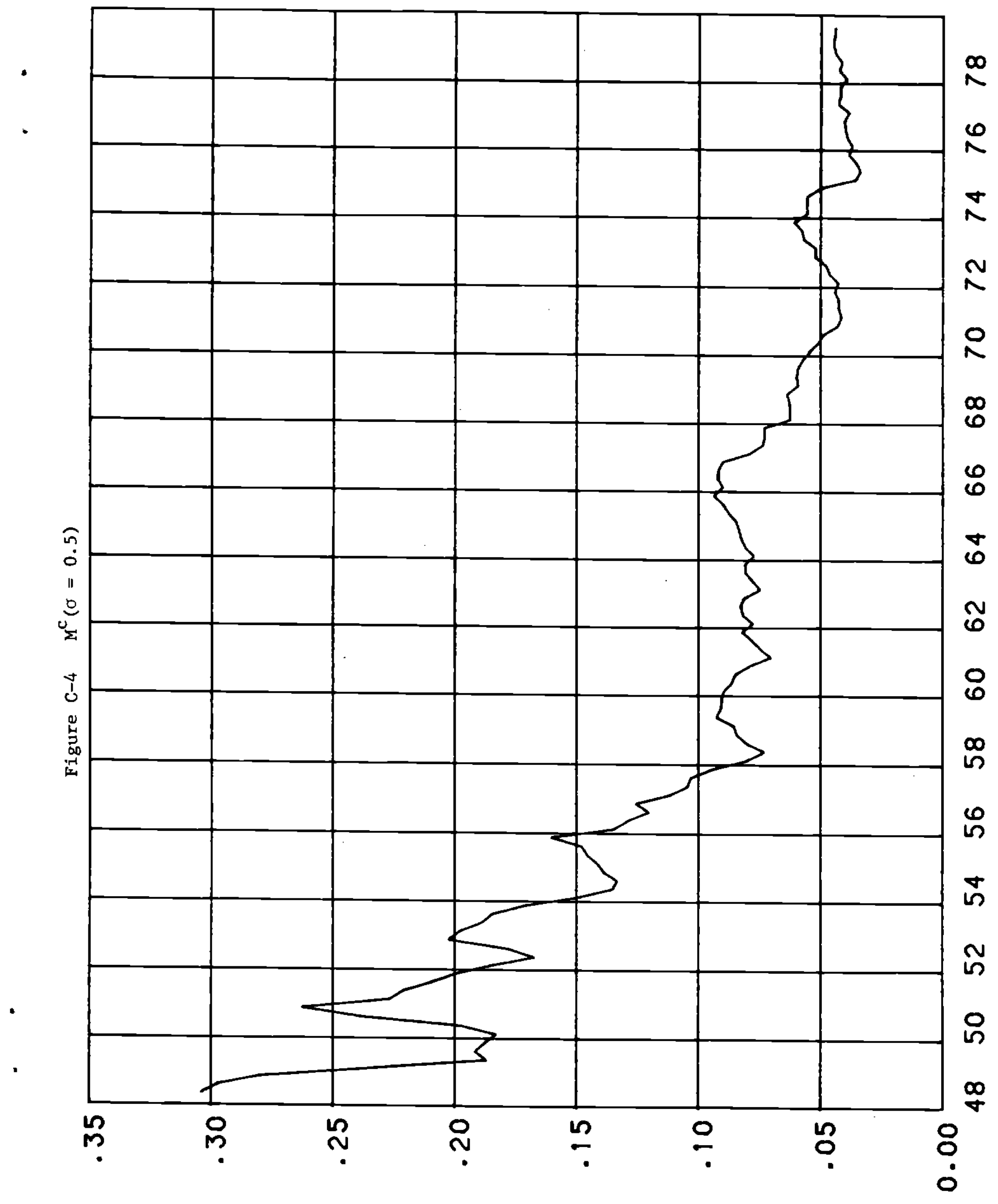




\section{References}

Abe1, A., "Empirical Investment Equations: An Integrative Framework," in $K$. Brunner and A. Heltzer, eds.. "On the State of Macroeconomis," Journal of Monetary Economics Supplement, 12, 1980, 39-91.

Bischoff, Charles W., "Business Investment in the 1970's: A Comparison of Mode1s," Brookings Papers on Economic Activity 1 (1971), 13-58.

Blanchard, O1ivier J, and Charles Vyplosz, "An Enpirical Structural llodel of Aggregate Demand," Journal of Monetary Econonics 7, 1 (January 1981), 128.

Breeden, D., "An Intertemporal Pricing Hodel with Stochastic Consumption and Investment," Journal of Financial Economics. 7, December 1979, 265-296.

Cicollo, J., "Four Essays in Honetary Policy," Ph.D. dissertation, Yale University, 1975.

Diamond, P., "The Role of a Stock Market in a General Equilibrium Model with Technological Uncertainty," American Economic Peview, 57-4, 1967, 759776 .

Eisner, Robert and Nadiri, H. I., "Investment Behavior and Neoclassical Theory," Review of Economics and Statistics, 50 (August 1968), 369-382.

Ha11, R. and D. Jorgenson, "Tax Policy and Investment Behavior," American Economic Review, 57-3, 1967, 391-414.

Lucas, Robert E. Jr., "Adjustment Costs and the Theory of Supply," Journal of Political Economy, 75 (August 1967), 321-334. 
- "Optimal Investment Policy and the Flexible Accelerator." International Economic Review 8 (February 1967), 78-85.

Modigliani, Franco and Robert J. Shiller, "Inflation, Rational Expectatiosn and the Term Structure of Interest Rates," Economica (February 1973), 12-43.

Shiller, R., "Do Stock Prices Move Too Huch to be Justified by Subsequent Changes in Dividends?" American Economic Review, 71-3, 1981, 421-436.

Summers, L., "Taxation and Corporate Investment: a q-Theory Approach," Brookings Papers on Economic Activity, 1981-1, 67-127.

Tobin, James, "A General Equilibrium Aproach to Monetary Theory." Journal of Honey, Credit and Banking 1 (February 1969), 15-29.

Von Furstenberg, G., "Corporate Investment: Does Market Valuation Matter. in the Aggregate?" Brookings Papers on Economic Activity, 1977-2, 347-397. 